Article

\title{
Studying the Reduction of Water Use in Integrated Solar Combined-Cycle Plants
}

\author{
Fontina Petrakopoulou * and Marina Olmeda-Delgado
}

Department of Thermal and Fluid Engineering, University Carlos III of Madrid, Avenida de la Universidad 30, Leganés, 28911 Madrid, Spain; marinaolmedadelgado@gmail.com

* Correspondence: fpetrako@ing.uc3m.es

Received: 24 January 2019; Accepted: 31 March 2019; Published: 8 April 2019

\begin{abstract}
With vast amounts of water consumed for electricity generation and water scarcity predicted to rise in the near future, the necessity to evaluate water consumption in power plants arises. Cooling systems are the main source of water consumption in thermoelectric power plants, since water is a cooling fluid with relatively low cost and high efficiency. This study evaluates the performance of two types of power plants: a natural gas combined-cycle and an integrated solar combined-cycle. Special focus is made on the cooling system used in the plants and its characteristics, such as water consumption, related costs, and fuel requirements. Wet, dry, and hybrid cooling systems are studied for each of the power plants. While water is used as the cooling fluid to condense the steam in wet cooling, dry cooling uses air circulated by a fan. Hybrid cooling presents an alternative that combines both methods. We find that hybrid cooling has the highest investment costs as it bears the sum of the costs of both wet and dry cooling systems. However, this system produces considerable fuel savings when compared to dry cooling, and a 50\% reduction in water consumption when compared to wet cooling. As expected, the wet cooling system has the highest exergetic efficiency, of 1 and 5 percentage points above that of dry cooling in the conventional combined-cycle and integrated solar combined-cycle, respectively, thus representing the lowest investment cost and highest water consumption among the three alternatives. Hybrid and dry cooling systems may be considered viable alternatives under increasing water costs, requiring better enforcement of the measures for sustainable water consumption in the energy sector.
\end{abstract}

Keywords: exergy; exergoeconomic analysis; cooling water system; power plant; energy and water nexus; integrated solar combined-cycle

\section{Introduction}

Economic development leads to an increase in water and electricity demand. Water scarcity, however, is expected to create severe social problems in the near future [1,2]. Water shortages will result in difficulties, such as access to drinking water, problems with personal hygiene and sanitation [3], and food shortage issues [4], which are already being experienced in some parts of the world. In addition, climate change will cause a further reduction of water resources and will also impact the properties of water, due to increasing temperatures, and are expected to be exacerbated in the near future [5]. Water shortages and changes in water quality will also have a great impact on the energy sector. Energy conversion and, particularly, thermoelectric power plants, consume vast amounts of water. Thermoelectric power plants use water as the cooling fluid in steam cycles. After generating power in the steam turbine, the steam is condensed through use of a cooling fluid, usually freshwater which is normally associated with lower costs and higher power plant efficiencies [6]. The water cooling systems are the main water consumers in power plants, and their efficiency is reduced at higher water 
temperatures [7]. The most commonly used cooling technologies in power plants are the once-through cooling system, recirculating wet cooling, dry cooling, and hybrid cooling.

In once-through cooling (open loop) systems, a large amount of water is withdrawn from a nearby water source. Part of the water is discharged back to the water source [8], and some is lost due to evaporation $[9,10]$. The high environmental impact of this method is mainly related to the large volumes of withdrawn water and the relatively high discharge temperature of the water, which is between 8 and $15{ }^{\circ} \mathrm{C}$ above the temperature of the withdrawn water. This can affect the average temperature of the water body and, as a consequence, the existing flora and fauna (e.g., through decreased oxygen solubility and increased respiration rates, which implies reduced oxygen in the water). Water temperature increases can affect the biological activity of aquatic organisms and make them vulnerable to chemical toxicity. In this context, growth has been observed to decrease by $10 \%$ per $1{ }^{\circ} \mathrm{C}$ of temperature increase. Once-through systems are currently being used only in older power plants, since more recent constructions (since the 1970s) are built with recirculating wet cooling systems [11]. Recirculating wet cooling systems include a cooling tower forming a closed loop system with the condenser of the plant. Water from the cooling tower is used in the condenser and is then returned to the cooling tower at a higher temperature. In the cooling tower, it is brought into contact with ambient air that lowers its temperature, such that it can be used again. From $2 \%$ to $3 \%$ of the water is lost by evaporation in the process, creating the necessity to supplement with the same quantity of water (make-up water) [12]. Dry cooling uses air as the cooling medium. Both water consumption and withdrawal are avoided, but this method is associated with higher costs [12] and lower plant efficiency as it requires a power input to drive the incorporated fan. The lower operational efficiency implies a loss of $2 \%-3 \%$ of power output that can increase up to $20 \%-30 \%$ when demand peaks in the summer and the efficiency of the cooling system decreases due to high ambient temperatures [13]. Hybrid cooling combines wet and dry cooling systems in parallel, or in series, that operate based on defined specifications [14].

This paper presents the evaluation of two power plants, i.e., a natural gas combined-cycle (NGCC) plant and a concentrated solar power integrated combined-cycle (ISCC) power plant, with three different water cooling systems. The motivation for the paper lies in the evident future water scarcity scenarios and their implications for power plant operation. The ISCC power plant is composed of a concentrated solar power (CSP) field, to generate additional steam to increase the power output of the steam turbine (ST) $[15,16]$, and a conventional NGCC. The combination of these technologies presents several advantages, including the reduction of fossil fuel consumption and $\mathrm{CO}_{2}$ emissions when compared to conventional combined-cycle [17], and cost reduction, when compared to a CSP power plant. Nevertheless, it implies a considerable increase in investment costs when compared to a conventional combined-cycle [15]. The three cooling technologies considered are (a) recirculating wet cooling, (b) dry cooling, and (c) hybrid cooling. The hybrid cooling alternative includes a recirculating wet and dry system connected in parallel $[14,18]$. During warmer days, the total mass flow of steam is condensed using the wet cooling system, while during colder days, the cooling system works in dry cooling mode. The plants are simulated in design and off-design mode, and are evaluated using exergetic, economic, and exergoeconomic analyses.

The performance of combined-cycles and ISCCs has been previously reported in several papers published in literature. Achour et al. (2018) evaluated the performance of an ISCC in south Algeria, obtaining higher solar-to-electricity and combined-cycle efficiencies during summer and sunny days [19]. Binamer et al. (2019) developed a mathematical model to assess the performance of an ISCC power plant in Kuwait, obtaining higher efficiencies than those of conventional plants in the same area, as well as a reduction in carbon emissions [20]. Calise et al. (2018) simulated a dynamic model of an ISCC and compared it to a conventional combined-cycle using thermoeconomic criteria and the case study of a plant located in Almeria (Spain) [21]. Their results showed higher efficiencies for the ISCC when compared to the conventional combined-cycle, while from an economic viewpoint, the profitability of the ISCC plant is highly affected by the capacity of the 
solar field. Bonforte et al. (2018) applied exergoeconomic and exergoenvironmental analyses to compare an ISCC gas turbine (ISCCGT) to a conventional combined-cycle gas turbine. The ISCCGT showed better environmental performance, since the lower fuel mass flow led to a reduction in greenhouse gas emissions [22]. Furthermore, they evaluated the change in capital cost with increasing solar hybridization and decreasing natural gas. Ameri and Mohammadzadeh (2018) presented the thermodynamic, thermoeconomic, and lifecycle assessment of an ISCC and compared it to a combined-cycle plant [23]. It was found that the environmental impact on human health and resource damage was lower with the ISCC, while ecosystem damage was lower for the combined-cycle plant, due to smaller land occupation.

The main novelty of this work is that it focuses on the use of water, presenting a comparative evaluation of cooling systems under different capacities and ambient conditions. Deeper water scarcity is expected to significantly affect electricity production in the near future. The need to develop more sustainable cooling options-that consume less water and allow higher power plant efficiencies at relatively low costs than the actual dry cooling systems-is indisputable. The reduction of water withdrawal and consumption in power plants would not only imply an environmental advantage in providing a way to sort out the issue of electric power generation in locations with water scarcity, but would also allow power plants to be less dependent on nearby water sources such that they could continuously supply electricity even in times of drought [24]. Lastly, the exergy-based analyses presented here allow for a complete and accurate evaluation of the plants and the cooling systems.

\section{Methodology}

\subsection{Exergetic Analysis}

Energetic analysis is based on the first law of thermodynamics and cannot reveal the real location and quantification of inefficiencies of energy systems and, therefore, can be misleading when used to evaluate an energy system [25]. Exergetic analysis, on the other hand, relies on the concept of exergy, and identifies the location and magnitude of thermodynamic inefficiencies in processes [22,26]. Exergy analysis offers also a more detailed assessment of power plant components, allowing for better comprehension of the operation of the plant overall, and making the design, evaluation, and optimization of power plants more effective [27]. Exergetic analysis can be further combined with economic and environmental issues in exergoeconomic and exergoenvironmental analyses [28,29].

In an exergetic analysis, the exergy of the fuel $\left(E_{F}\right)$, the exergy of the product $\left(E_{P}\right)$, and the exergy destruction $\left(E_{D}\right)$ of each component of an energy system are calculated. The fuel represents the expense of resources to generate a determined product, while the product is the desired outcome within the thermodynamic process [28]. The exergetic efficiency $(\varepsilon)$ is the ratio between the exergy of product and fuel, and is defined both at the component and plant level.

$$
\begin{gathered}
\varepsilon_{k / t o t}=\frac{E_{P, k / t o t}}{E_{F, k / t o t}} \times 100[\%] \\
E_{D, k / t o t}=E_{F, k / t o t}-E_{P, k / t o t}[M W]
\end{gathered}
$$

In the case of the overall system (tot), $E_{D}$ includes the exergy loss of the system $\left(E_{L, t o t}\right)$ :

$$
E_{D, t o t}=E_{F, t o t}-E_{P, t o t}-E_{L, t o t}[M W] .
$$

In this work, a MATLAB script has been used to perform exergetic analysis of the power plants. The program calculates the exergy of each stream of the plant, and exergy balances are later written at the component level.

Exergetic analysis has been applied elsewhere to evaluate energy conversion systems in numerous studies in the last decades (e.g., [30-33]). 


\subsection{Economic Analysis}

A detailed economic analysis was carried out for each simulated power plant. The investment costs were calculated for 2017, considered as the actual year. The fixed capital investment (FCI) of each plant component was estimated from its purchase equipment cost (PEC) using published references, and adapted to the capacity and year of the plants under consideration. For this purpose, the following equations were used $[34,35]$ :

$$
\begin{gathered}
C_{y}=C_{w} \times\left(\frac{X_{y}}{X_{W}}\right)^{\alpha}[€], \\
C_{\text {reference year }}=C_{\text {original year }} \times \frac{\text { Cost Index }}{\text { reference year }}[€],
\end{gathered}
$$

where $C_{y}$ is the calculated PEC at a given capacity $\left(X_{y}\right)$, and $C_{w}$ is the reference PEC of the same component with capacity $X_{W}$. The exponent $\alpha$ is usually less than one [34].

The investment cost rates $\left(\dot{Z}_{k}\right)$ in cent/s for the exergoeconomic analysis were computed from the investment costs of the plant components using the following equation:

$$
\dot{Z}_{k}=\frac{(\text { carrying charges }+O \& M)}{\left(P E C_{t o t} \times \tau\right)} \times P E C_{k}\left[\frac{€}{s}\right],
$$

where $\tau$ is the annual operating hours and O\&M are the operating and maintenance costs. Carrying charges result from the subtraction of O\&M and fuel costs from the total rate of return (TRR). These cost rates are inputs for the exergoeconomic analysis.

\subsection{Exergoeconomic Analysis}

Exergoeconomic analysis couples the results of the exergetic analysis with calculated costs. The total costs for each component are calculated by summing up the cost rate of exergy destruction $\left(\dot{C}_{D, k}\right)$ and the investment cost rate $\left(\dot{Z}_{k}\right)$. A higher total cost of a certain component shows a bigger impact of the component on the overall plant.

The exergoeconomic factor $(f)$ and relative cost difference $(r)$ are calculated at both the component $(k)$ and the plant level (tot) using the following equations.

$$
\begin{aligned}
f_{k / t o t} & =\frac{\dot{Z}_{k / t o t}}{\dot{C}_{D, k / t o t}+\dot{Z}_{k / t o t}}[-] \\
r_{k / t o t} & =\frac{c_{p, k / t o t}-c_{f, k / t o t}}{c_{f, k / t o t}}[-]
\end{aligned}
$$

$f_{k}$ is an indicator of the contribution of $\dot{Z}_{k}$ to the total cost $\left(\dot{C}_{D, k}+\dot{Z}_{k}\right)$. High values of $f_{k}$ suggest a high $\dot{Z}_{k}$, implying that reduction of the investment costs of the particular component should be considered. A low $f_{k}$ value implies a high $\dot{C}_{D, k}$, meaning that a reduction in exergy destruction of this component must be prioritized. $r_{k}$ is an indicator of the difference between the specific cost of product $\left(c_{p, k}\right)$ and fuel $\left(c_{f, k}\right)[35]$.

\section{Simulations}

The simulations of the plants were realized using the commercial software EBSILON Professional. For each power plant we realized three simulations, each with a different cooling system: wet recirculating, dry, and hybrid cooling. The gas turbine (GT) in all of the power plants was simulated as the heavy-duty GT of Siemens SGT5-4000F $(50 \mathrm{~Hz})$. The power output of the power plants was $427 \mathrm{MW}$, which was kept constant throughout the study. 


\subsection{Simulation of the NGCC}

A simplified flow diagram of the plant is shown in Figure 1, with operating parameters of the components found in Table 1. The steam turbine of the combined-cycle power plant has three pressure levels with a reheating stage before the intermediate-pressure steam turbine (IPST). The GT and ST power outputs are 285 and $143 \mathrm{MW}$, respectively, and the efficiency of the reference plant (NGCC with wet cooling system) is $58.2 \%$ (base case). The ambient temperature and pressure of the base case are $15{ }^{\circ} \mathrm{C}$ and 1.013 bar.

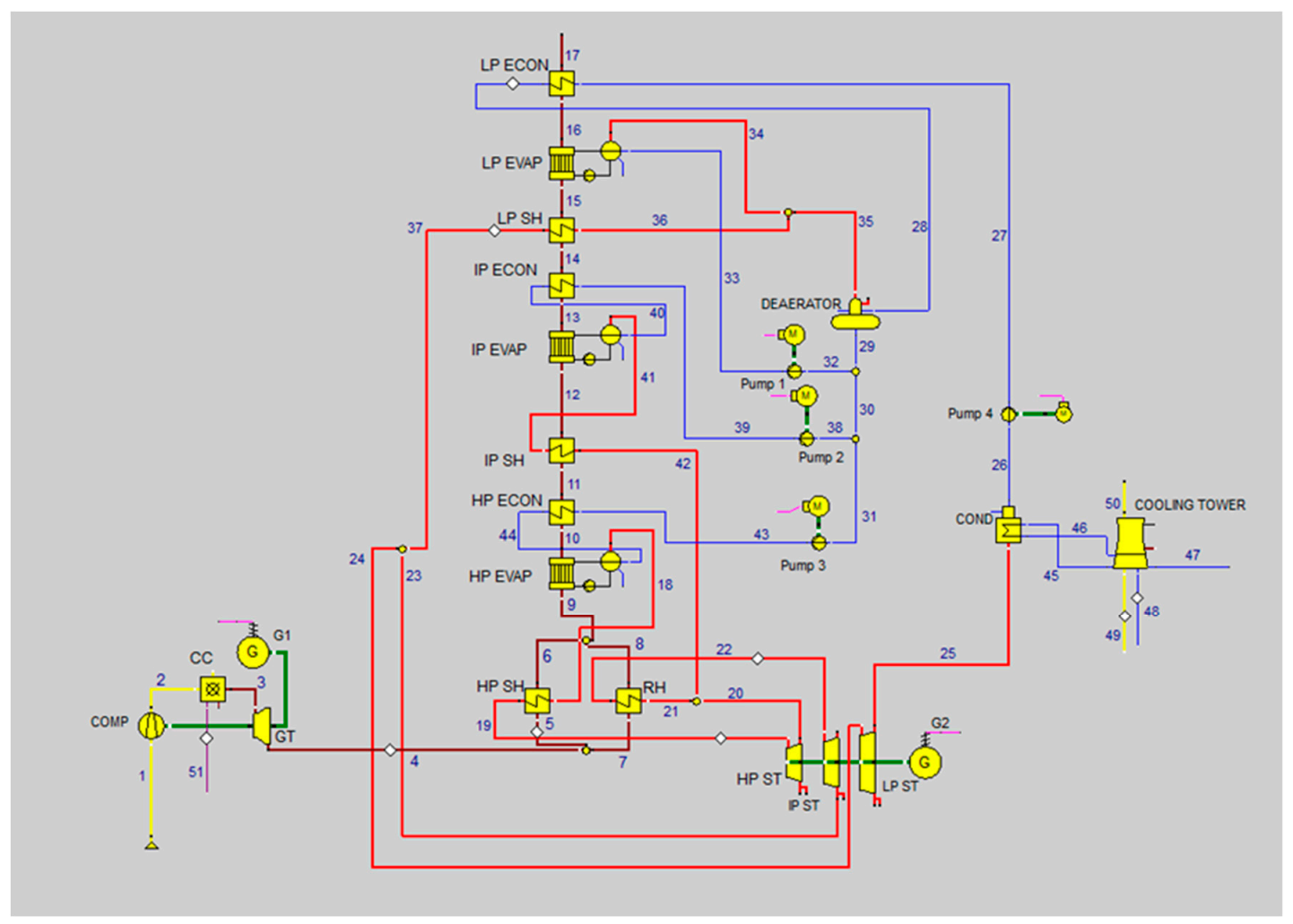

Figure 1. Natural gas combined-cycle (NGCC) power plant with wet cooling system.

Table 1. NGCC power plant operating parameters. HRSG: heat recovery steam generator; SH: superheater.

\begin{tabular}{l}
\hline Ambient Air \\
\hline $15^{\circ} \mathrm{C}, 1.013$ bar, $60 \%$ relative humidity \\
Composition (mol \%): $\mathrm{N}_{2}(75.04), \mathrm{O}_{2}(22.99), \mathrm{CO}_{2}(0.05), \mathrm{H}_{2} \mathrm{O}(0.63), \mathrm{Ar}(1.28)$ \\
\hline Fuel \\
\hline $14.66 \mathrm{~kg} / \mathrm{s}$ (wet cooling) $/ 14.91 \mathrm{~kg} / \mathrm{s}\left(\mathrm{dry}\right.$ cooling), $25^{\circ} \mathrm{C}, 17$ bar, $\mathrm{LHV}=50,015 \mathrm{~kJ} / \mathrm{kg}$ \\
Natural gas composition (mol \%): $\mathrm{CH}_{4}(100.0)$ \\
\hline Gas Turbine System \\
\hline Compressor: isentropic efficiency, $90.0 \%$; mechanical efficiency, $99 \%$; pressure ratio, 16.8 \\
Gas turbine: isentropic efficiency: $91 \%$; mechanical efficiency: $99 \%$ \\
Generators: electrical efficiency, $98.5 \%$ \\
\hline Steam Cycle Overall Plants \\
\hline HRSG: 1 reheat stage, 3 pressure levels: $\mathrm{HP}(125$ bar), IP $(25$ bar), LP $(5$ bar) \\
HRSG pressure drop: hot side, 5 mbar; cold side, $5 \%$ \\
SHs: $\Delta$ Tmin, $20{ }^{\circ} \mathrm{C}(\mathrm{HP}, \mathrm{LP}) ; \Delta \mathrm{Tmin}: 10{ }^{\circ} \mathrm{C}(\mathrm{IP})$ \\
EVAPs (HP, IP): approach temperature, $5{ }^{\circ} \mathrm{C} ;$ pinch point: $10{ }^{\circ} \mathrm{C}$ \\
EVAP (LP): approach temperature, given externally; pinch point: $10{ }^{\circ} \mathrm{C}$ \\
Live steam temperature: $563{ }^{\circ} \mathrm{C}$ \\
Steam turbine isentropic efficiency (HP, IP, LP): $92 \%$ \\
Steam turbine mechanical efficiency (HP, IP, LP): $99 \%$ \\
Pumps efficiencies: $85 \%-87.2 \%$ (incl. motors and mechanical efficiency: $98 \%-99.8 \%)$ \\
\hline
\end{tabular}


Table 1. Cont.

\begin{tabular}{l}
\hline Wet Cooling System \\
\hline Condenser operating pressure: $0.05 \mathrm{bar}$ \\
Cooling water temperature: $17.27^{\circ} \mathrm{C}$ \\
Make-up water mass flow: $102.84 \mathrm{~kg} / \mathrm{s}$ \\
Dry Cooling System \\
\hline Air-cooled condenser operating pressure: 0.05 bar \\
Cooling air temperature: $1^{\circ} \mathrm{C}$ \\
Power input to work the fan: $7.2 \mathrm{MW}$ \\
\hline
\end{tabular}

Natural gas with a mass flow of $14.7 \mathrm{~kg} / \mathrm{s}$ is injected to the combustion chamber (Stream 51). The maximum temperature of the whole cycle is achieved at the outlet of the combustion chamber (Stream $3,1240{ }^{\circ} \mathrm{C}$ ). The required fuel mass flow is slightly higher when the dry cooling system is used $(14.9 \mathrm{~kg} / \mathrm{s})$, since the power output of the plant is kept constant; here, some power is required to drive the dry cooling system. The heat recovery steam generator (HRSG) is comprised of three pressure levels, each of them with a superheater (SH), evaporator (EVAP), and economizer (ECON). Superheated steam enters the ST at 125 bar (Stream 19) and exits at the low-pressure (LP) end with a pressure of 0.05 bar (Stream 25). Then, the steam is condensed into liquid water and enters the HRSG to close the cycle.

In the case of the wet cooling system, the mass flow of the steam is $103.6 \mathrm{~kg} / \mathrm{s}$ (Stream 25) and is condensed by means of cooling water flowing at a rate of $9736.5 \mathrm{~kg} / \mathrm{s}$ (Stream 45). The cooling water is circulated between the condenser and the cooling tower, where the warmer water comes into contact with ambient air (Stream 49) used to decrease the temperature of the water. Some of the water is evaporated in the process and, therefore, lost. This lost water is made up through a stream with a mass flow of $102.8 \mathrm{~kg} / \mathrm{s}$ entering into the cooling tower (Stream 48). In the dry cooling system (modification shown on the left panel of Figure 2), the steam is condensed in an air condenser with a mass flow of air of $30,273.2 \mathrm{~kg} / \mathrm{s}$ (Stream 45), which is passed through the condenser using a fan driven with electricity. This causes an efficiency loss in the overall plant due to the power required to drive the fan (7.2 MW). In the case of the simulation with the hybrid cooling system (modification shown on the right panel of Figure 2), the performance was the same as that of the wet or dry cooling systems, depending on the active cooling mode. The dry cooling mode is used during colder months and the wet cooling mode is used during warmer months.

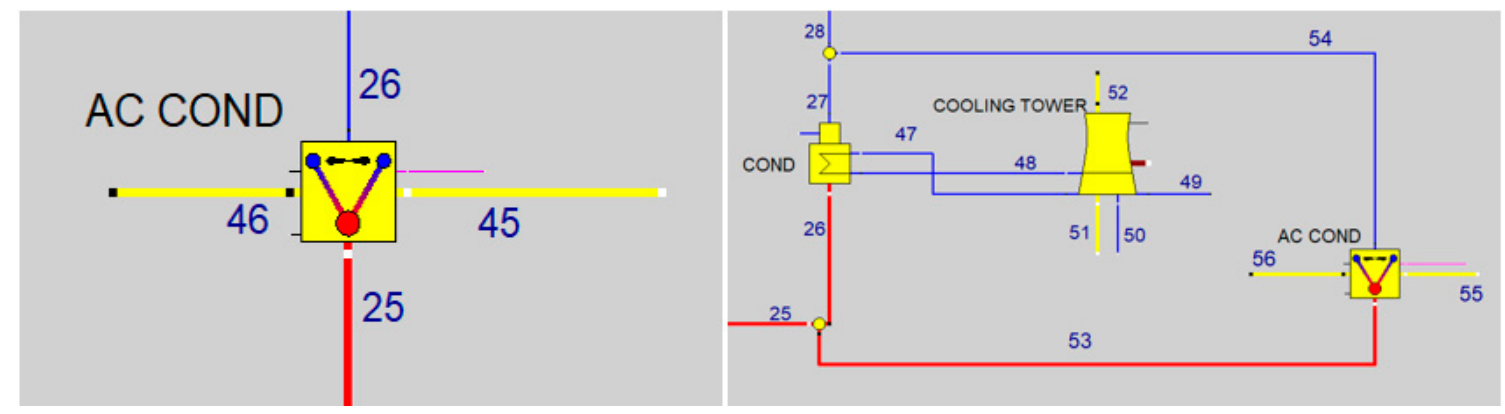

Figure 2. Variations for dry cooling (left panel) and hybrid cooling system (right panel).

The exergy balances used to calculate the $E_{F}, E_{P}$, and $E_{D}$ of each component of the NGCC power plant are shown in Table A1 of Appendix A.

\subsection{Simulation of the ISCC}

The CSP-integrated combined cycle consists of two parts: a parabolic trough solar field and an NGCC (Figure 3). The solar field heats up a thermal fluid that is then used to produce steam in a secondary HRSG (HRSG1). HRSG1 is coupled with the three-pressure level HRSG of the combined 
cycle (HRSG2). This additional steam provided by the solar field increases the power output of the ST when compared to the base NGCC. In order to achieve a total power output of the plant equal to that of the base NGCC, the power output of the gas turbine and, thus, the fuel it requires is reduced. This leads to a higher operational efficiency considering natural gas as the only fuel when calculating the efficiency of the plant. Since the solar part only works when solar energy is available, the plant operates as a normal combined cycle at night. The design simulation was realized for the 21 June (summer solstice) at 12:00 with a direct normal irradiation (DNI) of $950 \mathrm{~W} / \mathrm{m}^{2}$ and an ambient temperature of $33.4{ }^{\circ} \mathrm{C}$ (reference year: 2017). As mentioned above, three simulations of this power plant are realized with wet cooling, dry cooling and hybrid cooling systems. As the steam mass flow in the Rankine cycle of the ISCC is higher than in the base NGCC plant (due to the higher quantity of steam generated), the cooling system also requires, in this case, more cooling water (in the case of the wet cooling system) and higher power input to drive the fan (in the case of the dry cooling system). Operating parameters of the plant components are shown in Table 2.

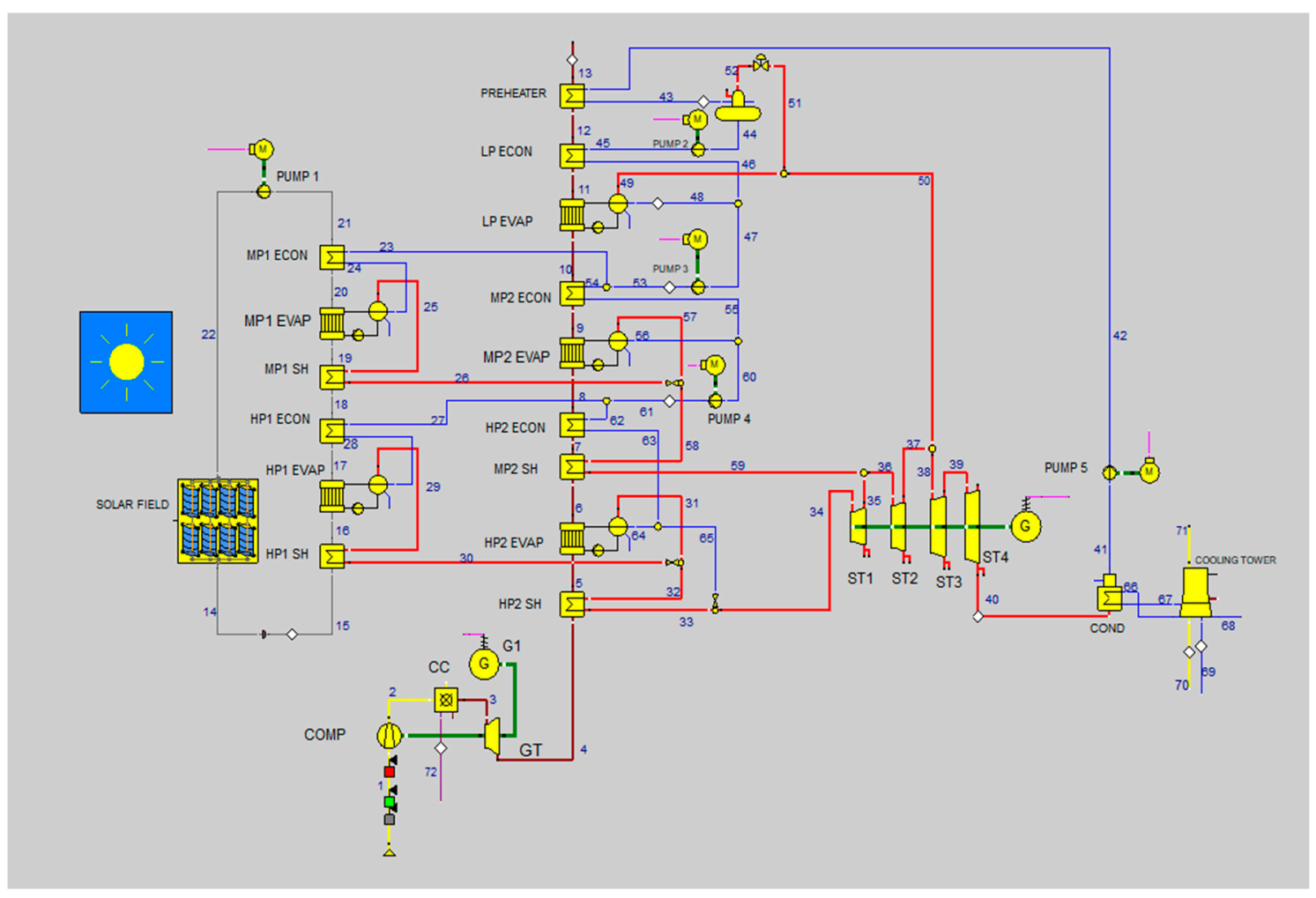

Figure 3. Integrated combined-cycle (ISCC) power plant with wet cooling system.

Table 2. ISCC power plant operating parameters. ECON: economizer; EVAP: evaporator.

\begin{tabular}{l}
\hline Ambient Air \\
\hline $33.4{ }^{\circ} \mathrm{C}, 1.013$ bar, $60 \%$ relative humidity \\
Composition (mol \%): $\mathrm{N}_{2}(74.07), \mathrm{O}_{2}(22.69), \mathrm{CO}_{2}(0.04), \mathrm{H}_{2} \mathrm{O}(1.93), \mathrm{Ar}(1.27)$ \\
\hline Fuel \\
\hline $11.37 \mathrm{~kg} / \mathrm{s}$ (wet cooling)/12.22 kg/s (dry cooling), $25^{\circ} \mathrm{C}, 15 \mathrm{bar}, \mathrm{LHV}=50,015 \mathrm{~kJ} / \mathrm{kg}$ \\
Natural gas composition (mol \%): $\mathrm{CH}_{4}(100.0)$ \\
\hline Gas Turbine System \\
Compressor: isentropic efficiency, $90.0 \%$; mechanical efficiency, $99 \%$; pressure ratio: 14.8 \\
Gas turbine: isentropic efficiency, $91 \%$; mechanical efficiency, $99 \%$ \\
Generators: electrical efficiency, $98.5 \%$
\end{tabular}


Table 2. Cont.

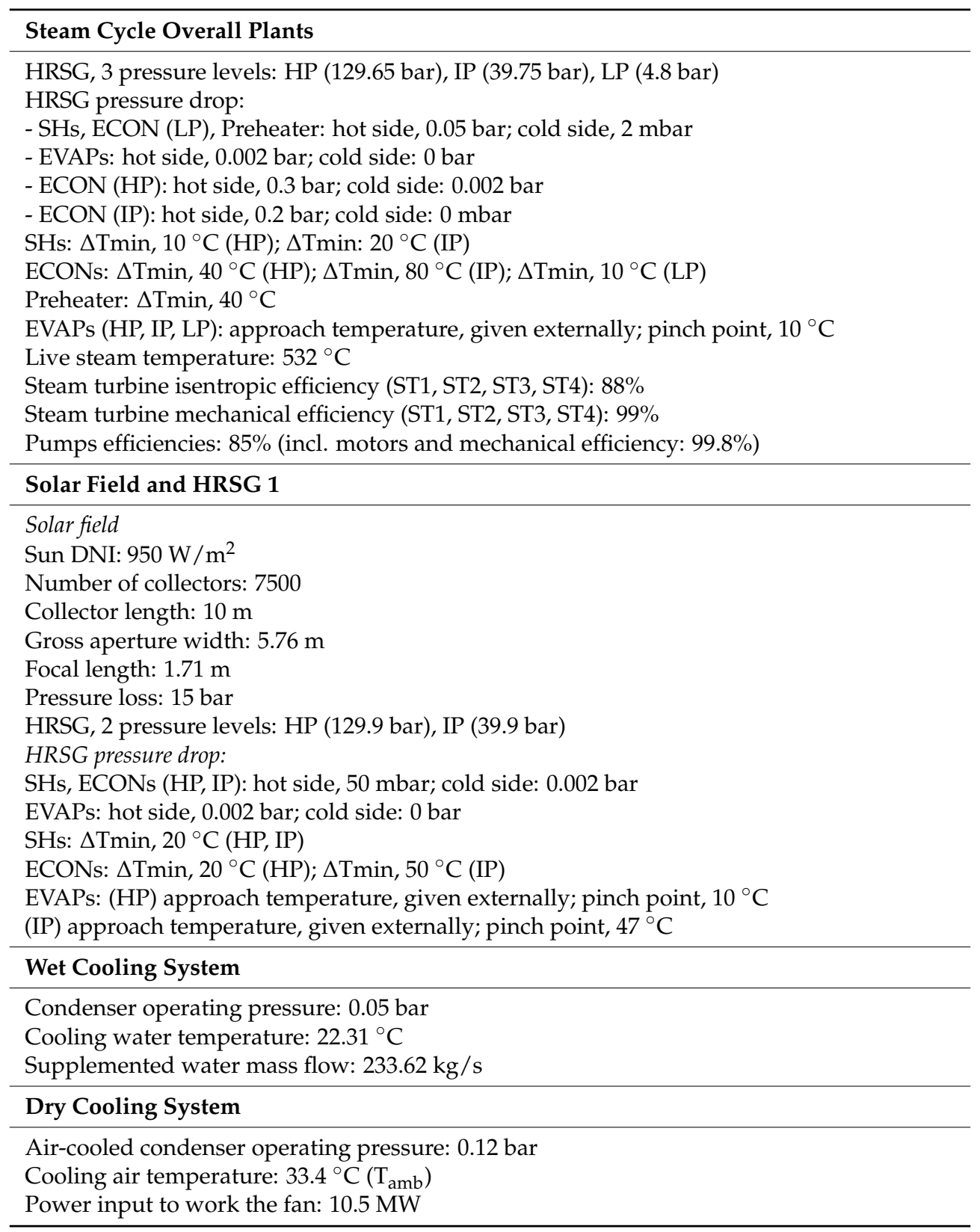

The fuel mass flow used in the combustion chamber for the static simulation (summer solstice, CSP field providing additional steam) is 11.4 and $12.2 \mathrm{~kg} / \mathrm{s}$ (Stream 72) with wet and dry cooling, respectively. The cycle reaches its maximum temperature (Stream $3,1231.9^{\circ} \mathrm{C}$ ) at the outlet of the combustion chamber. As in the base natural gas plant, HP steam enters the ST at 129.7 bar (Stream 34), and exits the LPST at 0.05 bar (Stream 40 ). In the case of the incorporation of the dry cooling system, the outlet pressure of the ST is 0.12 bar due to the high temperature of the air $\left(33.4^{\circ} \mathrm{C}\right.$, ambient temperature) in the air-cooled condenser; the steam exiting the steam turbine is then condensed into liquid water by passing through the cooling system of the plant.

When the wet cooling system is used, the mass flow of the steam to be condensed is $189.8 \mathrm{~kg} / \mathrm{s}$. Cooling water is circulated between the condenser and the cooling tower (Streams 66 and 67). The water flow is 16,207.3 kg/s (Stream 66) and air (Stream 70) is used to cool it down in order to be reused in the cooling system. The evaporation losses are compensated by a stream of supplemented water with a mass flow rate of $233.6 \mathrm{~kg} / \mathrm{s}$ (Stream 69). In the case of the dry cooling system, the steam is condensed 
with air at a rate of $41,567.6 \mathrm{~kg} / \mathrm{s}$. The power input to drive the fan of the cooling system is $10.5 \mathrm{MW}$, a value higher than that of the base NGCC plant, mainly due to the higher mass flow of steam that needs to be condensed here.

The exergy balances used to calculate the $E_{F}, E_{P}$, and $E_{D}$ for each component of the ISCC power plant are shown in Table A2 of Appendix A.

As the operation of the ISCC is highly dependent on weather conditions, it is convenient to consider such variations in order to better understand the performance of the plant. To do so, a dynamic simulation of the performance of the power plant throughout the year has been realized. Ambient data of five consecutive years (2005-2009) in Seville have been used to compute the mean ambient temperature and sun DNI at every hour and over the whole year. This hourly mean was used as input data for the dynamic simulation. The simulations show a higher ST power output during the warmest months of the year. This is when the solar effective heat is also higher, and the solar field provides more additional steam. During these months, and given the constant power output of the plant, there is a lower GT power output and, therefore, lower fuel consumption, which results in higher operational efficiencies. The average fuel mass flow of the power plant computed from the hourly data of the dynamic simulation, including night hours and cloudy days, was 13.2 and $13.5 \mathrm{~kg} / \mathrm{s}$ when wet and dry cooling were respectively used. The selected results for 10 days in January and 10 days in July are presented in Figures 4-6.

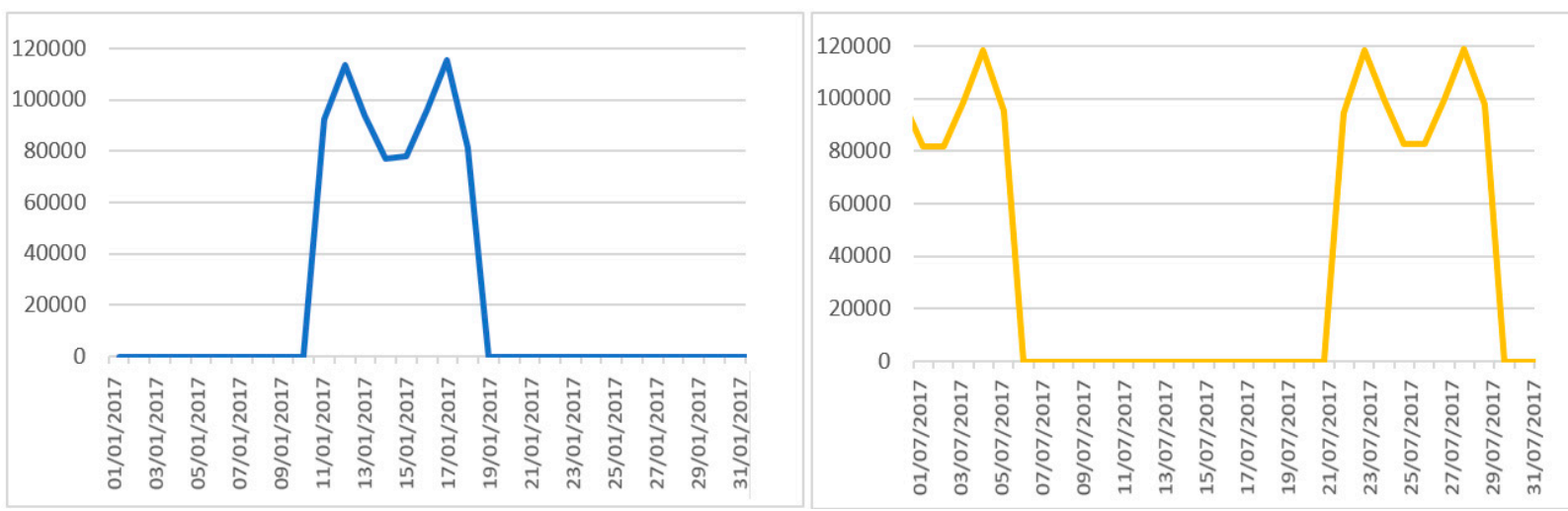

Figure 4. Solar effective heat $(\mathrm{kW})$ variation in January (left panel) and July (right panel).

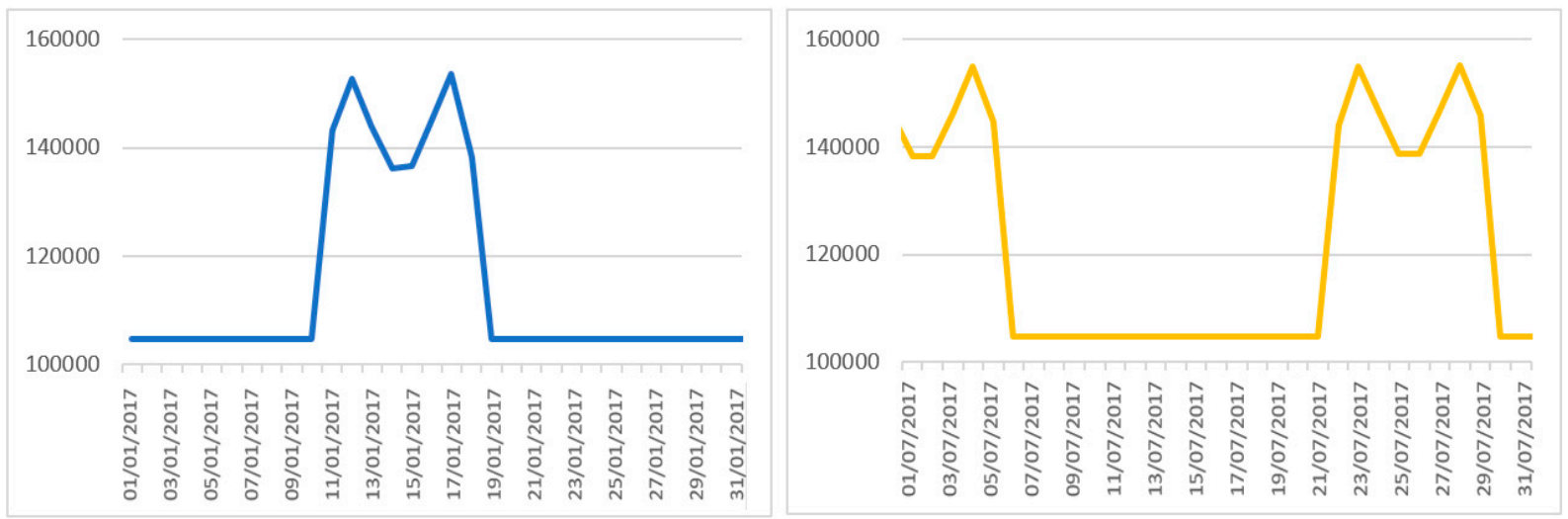

Figure 5. Steam turbine (ST) power output (kW) variation in January (left panel) and July (right panel). 


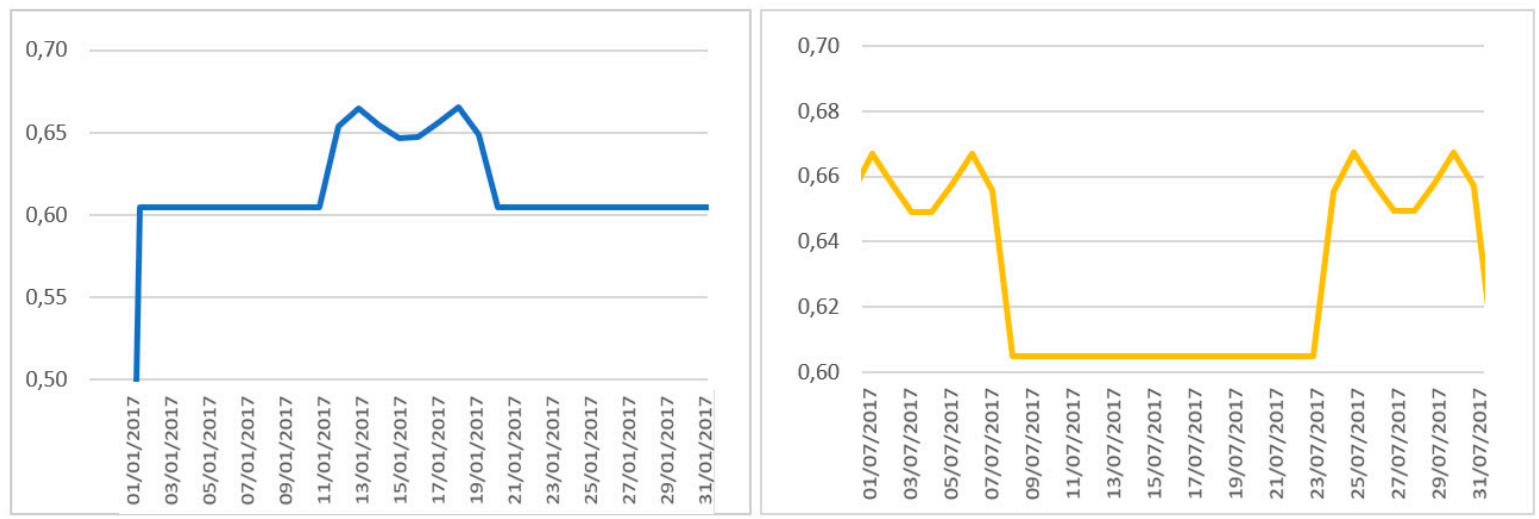

Figure 6. Efficiency of the combined-cycle plant in January (left panel) and July (right panel).

\section{Results}

Cooling water demand is an important focal point of this work. In this sense, when a wet cooling system is used, the water consumption is $0.74 \mathrm{~L} / \mathrm{kWh}$ in the NGCC, meaning 2.8 million $\mathrm{m}^{3}$ of water are consumed annually. In the case of the hybrid cooling system, the water consumption was reduced to half $\left(0.37 \mathrm{~L} / \mathrm{kWh}\right.$ and 1.4 million $\mathrm{m}^{3}$ annually), given that it works in wet cooling mode for half of the year. In the ISCC, the water consumption is considerably higher than in the NGCC. It reaches 1.68 and $0.84 \mathrm{~L} / \mathrm{kWh}$, which accounts for an annual water consumption of 6.37 and 3.2 million $\mathrm{m}^{3}$ when using the wet and hybrid cooling systems, respectively. This higher water consumption is due to the higher steam mass flow passing through the cooling system in the ISCC when compared to the NGCC. A capacity factor of $85 \%$ has been assumed for both the NGCC and the ISCC.

The $\mathrm{CO}_{2}$ emissions of the power plants depend on the types of cooling systems implemented and power plant technology used. Such differences lead to variations in the required fuel. The NGCC releases annually 1078.6, 1096.8, and $1087.7 \mathrm{kt}$ of $\mathrm{CO}_{2}$ when dry, wet, and hybrid cooling are used, respectively. The $\mathrm{CO}_{2}$ emissions of the ISCC are lower than that of the NGCC, due to the lower fuel mass flow required. This plant releases $987.4,1004.7$, and $996.0 \mathrm{kt}$ of $\mathrm{CO}_{2}$ with wet, dry, and hybrid cooling systems, respectively.

Detailed results of the exergetic, economic, and exergoeconomic analyses for all simulated plants at the stream and component level are listed in Tables A3-A10 of Appendix A of the paper, while selected results of the analyses are commented on below.

\subsection{Exergetic Analysis}

The main results of the exergetic analysis of both the NGCC and the ISCC are shown in Table 3. The power input necessary to drive the fan of the air-cooled condenser in the NGCC using dry cooling leads to a lower exergetic efficiency, compared to the same plant using wet cooling. This additional power use leads to a higher fuel consumption, which increases the total exergy of fuel of the plant $E_{F, t o t}$. Since the total power output is kept constant, the overall exergy of product, $E_{P, t o t}$, is very similar for all the simulated plants. The higher $\dot{E}_{F, \text { tot }}$ of the dry cooling simulation, the equal $\dot{E}_{P, t o t}$, and similar total exergy loss, $\dot{E}_{L, t o t}$, make the total exergy destruction, $\dot{E}_{D, t o t}\left(\dot{E}_{F, t o t}-\dot{E}_{P, t o t}-\dot{E}_{L, t o t}\right)$, of the simulation with the dry cooling system higher than that of wet cooling. When the NGCC is simulated with a hybrid cooling system, it reflects an exergetic efficiency between the ones achieved with the wet and dry cooling options. This is because the hybrid cooling system alternates between wet and dry cooling modes.

When looking at the component-level results of the NGCC plant with wet and dry cooling systems (Tables A7 and A8), the combustion chamber is identified as the component with the highest thermodynamic inefficiencies. In this case, $29.3 \%$ of the $\dot{E}_{F, t o t}$ is destroyed. This contributes to $71.2 \%$ and $71.6 \%$ of the total exergy destruction with wet and dry cooling, respectively. In the 
combustion chamber, the exergy destroyed is mainly due to the chemical reaction taking place there. Since the additional power input to drive the air-cooled condenser resulted in a higher mass flow of fuel, the exergy destruction of the combustion chamber when dry cooling was used is slightly higher (227.2 MW) than the one using wet cooling (223.4 MW). The next component with high contribution of exergy destruction is the expander of the gas turbine system, with $3.2 \%$ of the $\dot{E}_{F, t o t}$ being destroyed there. Exergy destruction within the gas turbine is mostly due to friction. In the dry cooling simulation, the exergy destruction within the air-cooled condenser is also high when compared to the other components, due to the higher $\dot{E}_{F}$ as a consequence of the fan power input. Among the remaining components, the HRSG is next in exergy destroyed, followed by the compressor of the gas turbine system.

Table 3. Results of the exergetic analysis for the NGCC and ISCC plants.

\begin{tabular}{ccccccc}
\hline \multirow{2}{*}{ Parameters } & \multicolumn{3}{c}{ NGCC } & \multicolumn{2}{c}{ ISCC } \\
\cline { 2 - 7 } & $\begin{array}{c}\text { Wet Cooling } \\
\text { Simulation }\end{array}$ & $\begin{array}{c}\text { Dry Cooling } \\
\text { Simulation }\end{array}$ & $\begin{array}{c}\text { Hybrid Cooling } \\
\text { Simulation }\end{array}$ & $\begin{array}{c}\text { Wet Cooling } \\
\text { Simulation }\end{array}$ & $\begin{array}{c}\text { Dry Cooling } \\
\text { Simulation }\end{array}$ & $\begin{array}{c}\text { Hybrid Cooling } \\
\text { Simulation }\end{array}$ \\
\hline$\varepsilon_{\text {tot }}(\%)$ & 57.3 & 56.4 & 56.8 & 73.8 & 68.7 & 71.2 \\
\hline$\dot{E}_{F \text { tot }}(\mathrm{MW})$ & 762.7 & 775.6 & 769.2 & 591.5 & 636.4 & 614.0 \\
\hline$\dot{E}_{P \text { tot }}(\mathrm{MW})$ & 437.3 & 437.5 & 437.1 & 436.5 & 437.1 & 437.1 \\
\hline$\dot{E}_{D \text { tot }}(\mathrm{MW})$ & 314.0 & 317.4 & 316.1 & 155.4 & 157.0 & 156.2 \\
\hline$y_{D \text { tot }}(\%)$ & 41.2 & 40.9 & 41.1 & 26.3 & 24.7 & 25.4 \\
\hline
\end{tabular}

In the ISCC, the combined-cycle efficiency ( $73.8 \%$ with wet cooling) was higher than that of the base NGCC (57.3\% with wet cooling), since the plant has smaller fuel consumption. Less fuel was required in this case because of the additional superheated steam provided by the solar field. This increased the steam turbine power output without the need for more fossil fuel input and, consequently, the exergy destruction of this plant was lower than that of the NGCC. As in the case of the NGCC, a difference between the wet and dry cooling systems was observed, this time, even greater. The higher steam mass flow in the Rankine cycle from the addition of the solar plant leads to a higher cooling demand, resulting in a relatively higher power input required for the dry cooling system. This power input was higher in the case of the ISCC than it was in the case of the NGCC causing, thus, a bigger difference in the total exergy of the fuel of the plant.

At the component level (Tables A9 and A10), the combustion chamber shows the highest exergy destruction (same as in the NGCC simulation), corresponding to $28.9 \%$ and $28.4 \%$ of the $\dot{E}_{F, t o t}$ of the plant with wet and dry cooling, respectively. The $\dot{E}_{D}$ within the combustion chamber was higher when using dry cooling, due to the higher fuel consumption. The next components in exergy destruction are the expander of the GT system and the cooling system components (condenser and cooling tower in wet cooling, and air-cooled condenser in dry cooling). In the HRSGs, the exergy destroyed in the HP level was higher than that of the IP and LP levels, mainly because of the higher temperatures on the hot side of the heat exchangers that increased the heat transfer.

The main results of the exergetic analysis of the dynamic simulation of the ISCC are shown in Table 4; since the plant produces additional steam using solar energy only when solar irradiation is available, the power plant operates as a conventional combined-cycle when the irradiation is unavailable. Given that the power output is constant, when the solar field is not providing additional steam, the fuel mass flow of the plant increases. This increases the average $\dot{E}_{F, \text { tot }}$ of the plant and lowers its efficiency. The ISCC allows a mean annual efficiency 6 percentage points higher than that of the NGCC. Since hybrid cooling works in both wet and dry cooling mode equally during the year, the exergetic results of the plant using this cooling system are between those obtained for the other two cooling technologies. 
Table 4. Results of the exergetic analysis for the ISCC dynamic simulation.

\begin{tabular}{cccc}
\hline $\begin{array}{c}\text { Dynamic Simulation } \\
\text { Results }\end{array}$ & $\begin{array}{c}\text { Wet Cooling } \\
\text { Simulation }\end{array}$ & $\begin{array}{c}\text { Dry Cooling } \\
\text { Simulation }\end{array}$ & $\begin{array}{c}\text { Hybrid Cooling } \\
\text { Simulation }\end{array}$ \\
\hline$\varepsilon_{\text {tot }}(\%)$ & 63.4 & 62.3 & 62.9 \\
$\dot{E}_{F}$ tot $(\mathrm{MW})$ & 689.0 & 701.1 & 695.0 \\
$\dot{E}_{P \text { tot }}(\mathrm{MW})$ & 436.5 & 437.1 & 437.1 \\
\hline
\end{tabular}

\subsection{Economic Analysis}

The main results of the economic analysis of each power plant are shown in Table 5. The FCI differences among the NGCC power plants stem from the cooling technology used. Dry cooling has a much higher investment cost than wet cooling. Hybrid cooling assumes operation as a wet cooling or as a dry cooling system, depending on the weather conditions. It is thus necessary that all components involved in the cooling systems are able to work at full capacity. The FCI of the plant with hybrid cooling includes, thus, the sum of the two cooling systems.

Table 5. Results of the economic analysis for the NGCC and ISCC plants.

\begin{tabular}{|c|c|c|c|c|c|c|}
\hline \multirow[b]{2}{*}{ Parameters } & \multicolumn{3}{|c|}{ NGCC } & \multicolumn{3}{|c|}{ ISCC } \\
\hline & $\begin{array}{l}\text { Wet Cooling } \\
\text { Simulation }\end{array}$ & $\begin{array}{c}\text { Dry Cooling } \\
\text { Simulation }\end{array}$ & $\begin{array}{l}\text { Hybrid Cooling } \\
\text { Simulation }\end{array}$ & $\begin{array}{l}\text { Wet Cooling } \\
\text { Simulation }\end{array}$ & $\begin{array}{l}\text { Dry Cooling } \\
\text { Simulation }\end{array}$ & $\begin{array}{l}\text { Hybrid Cooling } \\
\text { Simulation }\end{array}$ \\
\hline Total FCI (M€) & 204 & 214 & 218 & 385 & 411 & 417 \\
\hline $\begin{array}{c}\text { Cooling system } \\
\text { FCI (M€) }\end{array}$ & 4.2 & 13.6 & 17.8 & 6.1 & 26.4 & 32.4 \\
\hline
\end{tabular}

As the power output of the three power plants is the same, and considering that dry cooling technology requires power input for the fan of the air-cooled condenser, the amount of fuel needed for dry cooling is relatively higher. This makes the absolute total cost of fuel for the power plant with dry cooling higher than that of the same plant with wet cooling. The total cost of fuel for the plant using dry cooling is estimated to be $85.3 \mathrm{M} €$ /year for mid-2021 (2021 being the first year of commercial operation), while when using wet cooling, the cost of fuel reaches $83.9 \mathrm{M} €$ /year.

The FCI of the ISCC plant is considerably higher than that of the NGCC due to the addition of the solar part. At 160.9 M€, the component with the highest cost-and, thus, the highest impact on the total cost of the plant-is the parabolic trough field. Despite the high cost, CSP technology helps to save fuel whenever the ambient conditions allow it. In this case, the cooling systems have a higher FCI when compared to the NGCC, mainly due to the higher mass flow of steam in the Rankine cycle. This mass flow increase also causes higher cost differences between the different cooling systems.

The cost of fuel for the plant using dry cooling is estimated to be 77.2 M€/year for mid-2021 (first year of commercial operation), while for wet cooling, the cost of fuel reaches the $75.8 \mathrm{M} €$ /year. The cost of fuel was computed with the mean fuel mass flow of the hourly fuel mass flow throughout a year (dynamic simulation).

\subsection{Exergoeconomic Analysis}

Selected results obtained from the economic analysis of the plants are shown in Table 6. Due to its relatively lower investment cost and fuel consumption, wet cooling results in the lowest levelized cost of electricity (COE) in the case of the NGCC. Using the dry cooling system implies the highest $\mathrm{COE}$, followed closely by hybrid cooling. The COE is related to both the investment and the fuel used in each power plant. Calculations show that $77 \%$ of the total COE stems from fuel consumption, while only $23 \%$ is associated with investment. Even though the total investment cost rate, $\dot{Z}$, was higher for the hybrid cooling power plant, the fuel consumption was lower than that of the plant with dry cooling. This happens because the dry cooling infrastructure was only used for half of the year, 
reducing the power input of the fan to half of that needed in the plant with dry cooling. However, this fuel reduction does not imply a significant fuel variation. The COE of the power plant with hybrid cooling is thus found to be slightly lower than that of the power plant using dry cooling.

Table 6. Results of the exergoeconomic analysis for the NGCC and ISCC plants.

\begin{tabular}{ccccccc}
\hline \multirow{2}{*}{ Parameters } & \multicolumn{4}{c}{ NGCC } & \multicolumn{3}{c}{ ISCC } \\
\cline { 2 - 7 } & $\begin{array}{c}\text { Wet Cooling } \\
\text { Simulation }\end{array}$ & $\begin{array}{c}\text { Dry Cooling } \\
\text { Simulation }\end{array}$ & $\begin{array}{c}\text { Hybrid Cooling } \\
\text { Simulation }\end{array}$ & $\begin{array}{c}\text { Wet Cooling } \\
\text { Simulation }\end{array}$ & $\begin{array}{c}\text { Dry Cooling } \\
\text { Simulation }\end{array}$ & $\begin{array}{c}\text { Hybrid Cooling } \\
\text { Simulation }\end{array}$ \\
\hline COE $(\mathrm{cent} / \mathrm{kWh})$ & 6.10 & 6.24 & 6.23 & 6.06 & 6.48 & 6.39 \\
\hline$\dot{C}_{\text {Ftot }}(\mathrm{cent} / \mathrm{s})$ & 579.7 & 589.4 & 584.5 & 449.5 & 483.7 & 466.6 \\
\hline$\dot{Z}_{\text {tot }}(\mathrm{cent} / \mathrm{s})$ & 162.3 & 169.5 & 172.5 & 286.9 & 304.8 & 308.8 \\
\hline
\end{tabular}

When looking at the component-level results of all simulations with the three cooling systems (Tables A7-A10), the highest cost of exergy destruction, $\dot{C}_{D, k}$, was found for the combustion chamber. This is due to the high exergy destruction within this component. The expander of the GT system, the compressor and the LPST were next in $\dot{C}_{D, k}$ and total cost $\left(\dot{C}_{D, k}+\dot{Z}_{k}\right)$, in that order. Among the pressure levels of the HRSG, the highest $\dot{C}_{D, k}$ was found to be at the high-pressure level, and is explained by the higher exergy destruction there.

The exergoeconomic factor, $f_{k}$, was relatively high in the HPSH and IPEVAP within the HRSG, which means that a reduction in the investment costs of these components should be considered. The $f_{k}$ of the combustion chamber was low due to its high $\dot{C}_{D, k}$ when compared to its $\dot{Z}_{k}$, as caused by the high exergy destruction in this component.

In the case of the ISCC, the COE of the wet cooling alternative was even lower than that of the NGCC plant. This is due to the already explained contribution of both investment cost rate and fuel cost rate to the COE, and the fact that the fuel use in the ISCC is highly reduced when compared to the NGCC (even though the investment cost of the ISCC is much higher). However, when using dry cooling, the COE was considerably higher than in the NGCC plant. We also observed a larger difference among the COE of the ISCC plants with different cooling technologies than in the NGCC, which is due to the higher steam mass flow passing through the cooling systems, increasing the power input of the air-cooled condenser. The difference in fuel consumption due to the cooling system determines the differences among the calculated COE.

The $f_{k}$ of the pumps of the plants was relatively low, suggesting a potential reduction in the exergy destruction of these components. A low value of $f_{k}$ was found for the combustion chamber, as its $\dot{C}_{D, k}$ highly exceeds its $\dot{Z}_{k}$. Investment cost reductions should be considered for the components of the HRSGs of the plants.

\section{Conclusions}

This work evaluated and compared the thermodynamic and economic performance of a conventional combined-cycle power plant and an integrated solar combined-cycle plant with three cooling systems. The average fuel mass flow reduction in the solar-assisted plant, in comparison to the conventional combined-cycle, was 1.41 and $1.43 \mathrm{~kg} / \mathrm{s}$, with wet and dry cooling, respectively. The lower fuel mass flow led to $91.2 \mathrm{kt}$ less $\mathrm{CO}_{2}$ emissions in the integrated solar combined-cycle than in the base plant when using wet cooling, and $92.1 \mathrm{kt}$ less when using dry cooling. Overall, the total fuel saved in the solar-integrated power plant implies an important fuel cost reduction, and resulted in a mean annual operational efficiency six percentage points higher. Nevertheless, the higher steam mass flow in the plant due to the additional input from the solar part requires a larger cooling system capacity ( 6.3 vs. 2.8 million $\mathrm{m}^{3}$ of cooling water per year), increasing the cooling system investment costs. A comparison between the conventional combined-cycle and the integrated solar-combined cycle is shown in Table 7. 
Table 7. Comparison between the NGCC and the ISCC plants.

\begin{tabular}{ll}
\hline \multicolumn{1}{c}{ NGCC } & \multicolumn{1}{c}{ ISCC } \\
\hline Higher fuel consumption & Lower fuel consumption: higher efficiency \\
\hline $\begin{array}{l}\text { Continuous performance, independent } \\
\text { from ambient conditions }\end{array}$ & Performance depends on the ambient conditions \\
\hline Lower cooling system capacity & $\begin{array}{l}\text { Solar field provides the ST with additional steam } \rightarrow \text { Higher steam } \\
\text { mass flow passing through the cooling system (higher cooling } \\
\text { system capacity) }\end{array}$ \\
\hline Lower investment cost & Much higher investment cost due to the addition of the solar field \\
\hline
\end{tabular}

When comparing the different cooling systems, the highest water consumption takes place, as expected, with wet cooling, followed by hybrid cooling that works in wet cooling mode for half of the year. Wet cooling was also found to have the lowest cost of electricity, as its investment cost rate and fuel consumption were the lowest when compared to the other cooling systems. The highest investment cost was found for the hybrid cooling system, as it includes both wet and dry cooling technologies. Nevertheless, the dry cooling system investment cost is significantly higher than that of the wet cooling system. Dry cooling also led to the highest cost of electricity among all cooling technologies (1.4 and 4.8€/MWh higher than that of wet cooling in the base and the integrated solar combined plant, respectively). When looking at the $\mathrm{CO}_{2}$ emissions, our calculations show that switching from a dry cooling system to a hybrid cooling system can save up to $9 \mathrm{kt}$ of $\mathrm{CO}_{2}$ per year of operation in the case of the base plant, and $8.6 \mathrm{kt}$ in the integrated solar combined-cycle. A comparison between the wet, dry, and hybrid cooling systems is shown in Table 8.

Table 8. Comparison between wet, dry, and hybrid cooling.

\begin{tabular}{lll}
\hline \multicolumn{1}{c}{ Wet Cooling } & \multicolumn{1}{c}{ Dry Cooling } & \multicolumn{1}{c}{ Hybrid Cooling } \\
\hline Highest water consumption & $\begin{array}{l}\text { Approximately zero water } \\
\text { consumption }\end{array}$ & Half the water consumption of the wet cooling \\
\hline Lowest investment cost & High investment cost & $\begin{array}{l}\text { Highest investment cost: sum of the wet } \\
\text { cooling and the dry cooling investment costs }\end{array}$ \\
\hline $\begin{array}{l}\text { Zero power input required in } \\
\text { the cooling system }\end{array}$ & $\begin{array}{l}\text { Power input required to work } \\
\text { the air-cooled condenser fan }\end{array}$ & $\begin{array}{l}\text { Requires power input: half of the power input } \\
\text { required for the dry cooling }\end{array}$ \\
\hline Lowest COE & Highest COE & $\begin{array}{l}\text { COE in between that of the wet and dry } \\
\text { cooling systems }\end{array}$ \\
\hline
\end{tabular}

Nowadays, most power plants use closed wet-recirculating cooling systems, mainly because of the relatively efficient and economical operation of the technology when compared with dry cooling, and a lower environmental impact when compared to open-loop systems (once-through cooling). However, with rising global water scarcity and other environmental concerns, there is a need to incorporate cooling options with lower water consumption. Hybrid cooling presents an option that allows higher power plant efficiencies when compared to dry cooling, but also lower water consumption than wet cooling. This also results in a lower cost of electricity and significantly lower $\mathrm{CO}_{2}$ emissions than dry cooling (assuming relatively low cost of water) and thus can be considered a viable future option for cooling systems.

Author Contributions: Conceptualization, F.P.; Investigation, M.O.-D., F.P.; Project Administration, F.P.; Supervision, F.P.; Writing—Original Draft, M.O.-D., F.P.

Funding: Ministerio de Ciencia e Innovación: RYC-2016-20971.

Acknowledgments: Fontina Petrakopoulou would like to thank the Spanish Ministry of Science, Innovation and the Universidad Carlos III de Madrid (Ramón y Cajal Programme, RYC-2016-20971).

Conflicts of Interest: The authors declare no conflict of interest. 


\section{Nomenclature}

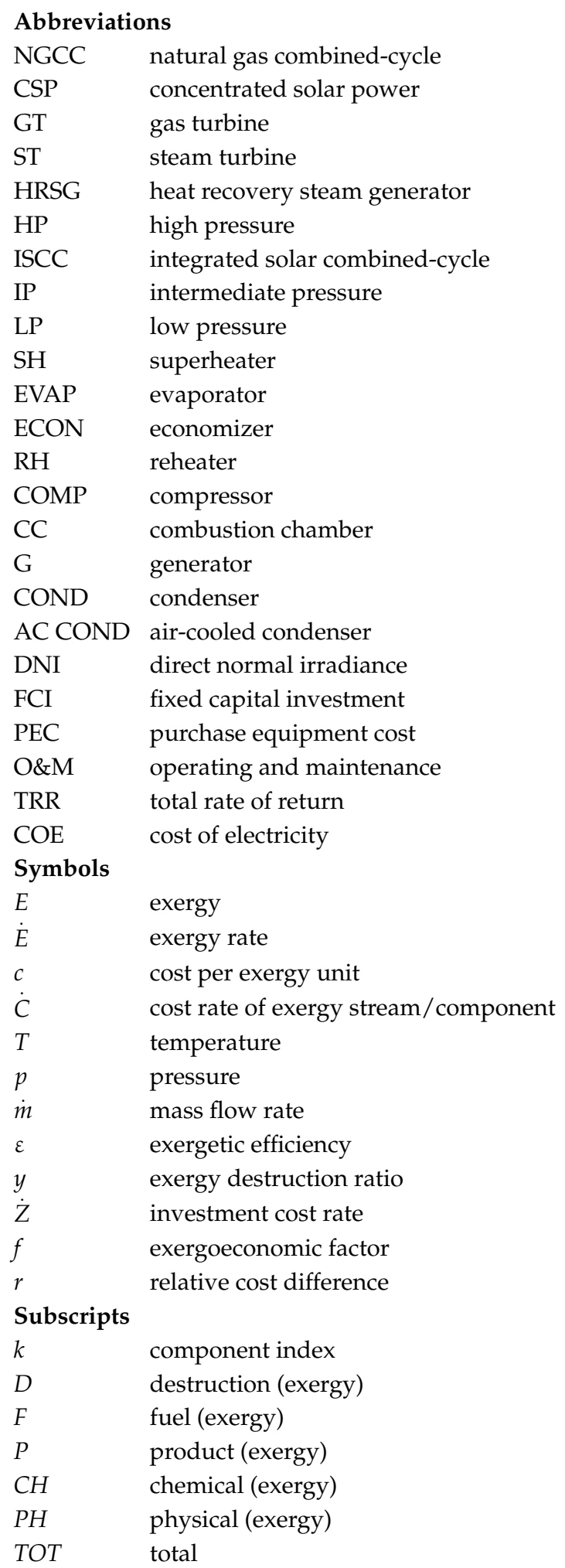




\section{Appendix A}

Table A1. Exergy balances of the NGCC power plant at the component level.

\begin{tabular}{|c|c|c|c|}
\hline Component & Exergy of the Fuel & Exergy of the Product & Exergy Destruction \\
\hline Compressor & $\begin{array}{c}E_{F, \text { Comp }}=W_{\text {Comp }}= \\
\dot{m}\left(h_{2}-h_{1}\right)\end{array}$ & $E_{P, \text { comp }}=E_{2}-E_{1}$ & $E_{D, c o m p}=E_{F, c o m p}-E_{P, c o m p}$ \\
\hline $\mathrm{CC}$ & $E_{F, c c}=E_{51}$ & $E_{P, c c}=E_{3}-E_{2}$ & $E_{D, c c}=E_{F, c c}-E_{P, c c}$ \\
\hline GT & $E_{F, G T}=E_{3}-E_{4}$ & $\begin{array}{c}E_{P, G T}=W_{G T}+W_{c o m p}= \\
\dot{m}\left(h_{3}-h_{4}\right) * n_{e l}\end{array}$ & $E_{D, G T}=E_{F, G T}-E_{P, G T}$ \\
\hline $\mathrm{HPSH}$ & $E_{F, H P S H}=E_{5}-E_{6}$ & $E_{P, H P S H}=E_{19}-E_{18}$ & $E_{D, H P S H}=E_{F, H P S H}-E_{P, H P S H}$ \\
\hline RH & $E_{F, R H}=E_{7}-E_{8}$ & $E_{P, R H}=E_{22}-E_{21}$ & $E_{D, R H}=E_{F, R H}-E_{P, R H}$ \\
\hline HPEvap & $E_{F, H P E v a p}=E_{9}-E_{10}$ & $E_{P, \text { HPEvap }}=E_{18}-E_{44}$ & $\begin{array}{c}E_{D, \text { HPEvap }}= \\
E_{F, \text { HPEvap }}-E_{P, \text { HPEvap }}\end{array}$ \\
\hline HPEcon & $E_{F, H P E c o n}=E_{10}-E_{11}$ & $E_{P, H P E c o n}=E_{44}-E_{43}$ & $\begin{array}{c}E_{D, H P E c o n}= \\
E_{F, H P E c o n}-E_{P, H P E c o n}\end{array}$ \\
\hline IPSH & $E_{F, I P S H}=E_{11}-E_{12}$ & $E_{P, I P S H}=E_{42}-E_{41}$ & $E_{D, I P S H}=E_{F, I P S H}-E_{P, I P S H}$ \\
\hline IPEvap & $E_{F, I P E v a p}=E_{12}-E_{13}$ & $E_{P, I P \text { Evap }}=E_{41}-E_{40}$ & $E_{D, I P E v a p}=E_{F 9}-E_{P 9}$ \\
\hline IPEcon & $E_{F, I P E c o n}=E_{13}-E_{14}$ & $E_{P, I P E c o n}=E_{40}-E_{39}$ & $E_{D, I P E c o n}=E_{F, I P E c o n}-E_{P, I P E c o n}$ \\
\hline LPSH & $E_{F, L P S H}=E_{14}-E_{15}$ & $E_{P, L P S H}=E_{37}-E_{36}$ & $E_{D, L P S H}=E_{F, L P S H}-E_{P, L P S H}$ \\
\hline LPEvap & $E_{F, \text { LPEvap }}=E_{15}-E_{16}$ & $E_{P, L P E v a p}=E_{34}-E_{33}$ & $E_{D, L P E v a p}=E_{F, L P E v a p}-E_{P, L P E v a p}$ \\
\hline LPEcon & $E_{F, L P E c o n}=E_{16}-E_{17}$ & $E_{P, L P E c o n}=E_{28}-E_{27}$ & $E_{D, L P E c o n}=E_{F, L P E c o n}-E_{P L P E c o n}$ \\
\hline HPST & $E_{F, H P S T}=E_{19}-E_{20}$ & $\begin{array}{c}E_{P, H P S T}=W_{H P S T}= \\
\dot{m}\left(h_{19}-h_{20}\right) * n_{e l}\end{array}$ & $E_{D, H P S T}=E_{F, H P S T}-E_{P, H P S T}$ \\
\hline MPST & $E_{F, M P S T}=E_{22}-E_{23}$ & $\begin{array}{c}E_{P, M P S T}=W_{M P S T}= \\
\quad \dot{m}\left(h_{22}-h_{23}\right) * n_{e l}\end{array}$ & $E_{D, M P S T}=E_{F, M P S T}-E_{P, M P S T}$ \\
\hline LPST & $E_{F, L P S T}=E_{24}-E_{25}$ & $\begin{array}{l}E_{P, L P S T}=W_{14}= \\
\dot{m}\left(h_{24}-h_{25}\right) * n_{e l}\end{array}$ & $E_{D, L P S T}=E_{F, L P S T}-E_{P, L P S T}$ \\
\hline P1 & $\begin{array}{c}E_{F, P 1}=W_{P 1}= \\
\dot{m}\left(h_{33}-h_{32}\right) / n_{e l}\end{array}$ & $E_{P, P 1}=E_{33}-E_{32}$ & $E_{D, P 1}=E_{F, P 1}-E_{P, P 1}$ \\
\hline P2 & $\begin{array}{c}E_{F, P 2}=W_{P 2}= \\
\dot{m}\left(h_{39}-h_{38}\right) / n_{e l}\end{array}$ & $E_{P, P 2}=E_{39}-E_{38}$ & $E_{D, P 2}=E_{F, P 2}-E_{P, P 2}$ \\
\hline P3 & $\begin{array}{c}E_{F, P 3}=W_{P 3}= \\
\dot{m}\left(h_{43}-h_{31}\right) / n_{e l}\end{array}$ & $E_{P, P 3}=E_{43}-E_{31}$ & $E_{D, P 3}=E_{F, P 3}-E_{P, P 3}$ \\
\hline P4 & $\begin{array}{c}E_{F, P 4}=W_{P 4}= \\
\dot{m}\left(h_{27}-h_{26}\right) / n_{e l}\end{array}$ & $E_{P, P 4}=E_{27}-E_{26}$ & $E_{D, P 4}=E_{F, P 4}-E_{P, P 4}$ \\
\hline Cond & - & - & $E_{D, \text { Cond }}=E_{25}-E_{26}+E_{45}-E_{46}$ \\
\hline Cooling Tower & - & - & $\begin{array}{c}E_{D, C T}= \\
E_{48}+E_{46}+E_{49}-E_{45}-E_{47}-E_{50}\end{array}$ \\
\hline Deaerator & $\begin{array}{c}E_{F, \text { Deaereator }}= \\
m_{35} \times\left(\frac{E_{35}}{m_{35}}-\frac{E_{29}}{m_{29}}\right)\end{array}$ & $\begin{array}{c}E_{P, \text { Deaerator }}= \\
m_{28} \times\left(\frac{E_{29}}{m_{29}}-\frac{E_{28}}{m_{28}}\right)\end{array}$ & $\begin{array}{c}E_{D, \text { Deaerator }}= \\
E_{F, \text { Deaerator }}-E_{P, \text { Deaerator }}\end{array}$ \\
\hline mixer 1 & $E_{F, M 1}=m_{23} \times\left(\frac{E_{23}}{m_{23}}-\frac{E_{24}}{m_{24}}\right)$ & $E_{P, M 1}=m_{37} \times\left(\frac{E_{24}}{m_{24}}-\frac{E_{37}}{m_{37}}\right)$ & $E_{D, M 1}=E_{F, M 1}-E_{P, M 1}$ \\
\hline mixer 2 & $E_{F, M 2}=m_{20} \times\left(\frac{E_{20}}{m_{20}}-\frac{E_{21}}{m_{21}}\right)$ & $E_{P, M 2}=m_{42} \times\left(\frac{E_{21}}{m_{21}}-\frac{E_{42}}{m_{42}}\right)$ & $E_{D, M 2}=E_{F, M 2}-E_{P, M 2}$ \\
\hline mixer 3 & $E_{F, M 3}=m_{8} \times\left(\frac{E_{8}}{m_{8}}-\frac{E_{9}}{m_{9}}\right)$ & $E_{P, M 3}=m_{6} \times\left(\frac{E_{9}}{m_{9}}-\frac{E_{6}}{m_{6}}\right)$ & $E_{D, M 3}=E_{F, M 3}-E_{P, M 3}$ \\
\hline Total & $E_{F, t o t}=E_{1}+E_{51}$ & $E_{P, t o t}=W_{t o t}$ & $\begin{array}{c}E_{D, \text { tot }}= \\
E_{F, \text { tot }}-E_{P, \text { tot }}-E_{L, t o t} * * E_{L, t o t}= \\
E_{17}+E_{47}+E_{50}-E_{48}-E_{49}\end{array}$ \\
\hline
\end{tabular}


Table A2. Exergy balances of the ISCC power plant at the component level.

\begin{tabular}{|c|c|c|c|}
\hline Component & Exergy of the Fuel & Exergy of the Product & Exergy Destruction \\
\hline Compressor & $\begin{array}{c}E_{F, \text { Comp }}=W_{\text {Comp }}= \\
\dot{m}\left(h_{2}-h_{52}\right)\end{array}$ & $E_{P, \text { Comp }}=E_{2}-E_{52}$ & $E_{D, \text { Comp }}=E_{F, \text { Comp }}-E_{P, \text { Comp }}$ \\
\hline $\mathrm{CC}$ & $E_{F, C C}=E_{72}$ & $E_{P, C C}=E_{3}-E_{2}$ & $E_{D, C C}=E_{F, C C}-E_{P, C C}$ \\
\hline GT & $E_{F, G T}=E_{3}-E_{4}$ & $\begin{array}{c}E_{P, G T}=W_{G T}+W_{C o m p}= \\
\dot{m}\left(h_{3}-h_{4}\right) * n_{e l}\end{array}$ & $E_{D, G T}=E_{F, G T}-E_{P, G T}$ \\
\hline $\mathrm{HP} 2 \mathrm{SH}$ & $E_{F, H P 2 S H}=E_{4}-E_{5}$ & $E_{P, H P 2 S H}=E_{33}-E_{32}$ & $E_{D, H P 2 S H}=E_{F, H P 2 S H}-E_{P, H P 2 S H}$ \\
\hline HP2 Evap & $E_{F, H P 2 E v a p}=E_{5}-E_{6}$ & $E_{P H P 2 E v a p}=E_{31}-E_{64}$ & $\begin{array}{c}E_{D, H P 2 E v a p}= \\
E_{F, H P 2 E v a p}-E_{P, H P 2 E v a p}\end{array}$ \\
\hline IP2 SH & $E_{F, I P 2 S H}=E_{6}-E_{7}$ & $E_{P, I P 2 S H}=E_{59}-E_{58}$ & $E_{D, I P 2 S H}=E_{F, I P 2 S H}-E_{P, I P 2 S H}$ \\
\hline HP2 Econ & $E_{F, H P 2 E c o n}=E_{7}-E_{8}$ & $E_{P, H P 2 E c o n}=E_{63}-E_{62}$ & $\begin{array}{c}E_{D, H P 2 E c o n}= \\
E_{F, H P 2 E c o n}-E_{P, H P 2 E c o n}\end{array}$ \\
\hline IP2 Evap & $E_{F, I P 2 \text { Evap }}=E_{8}-E_{9}$ & $E_{P, I P 2 \text { Evap }}=E_{57}-E_{56}$ & $E_{D, I P 2 E v a p}=E_{F, I P 2 E v a p}-E_{P, I P 2 E v a p}$ \\
\hline IP2 Econ & $E_{F, I P 2 E c o n}=E_{9}-E_{10}$ & $E_{P, I P 2 E c o n}=E_{55}-E_{54}$ & $E_{D, I P 2 E c o n}=E_{F, I P 2 E c o n}-E_{P, I P 2 E c o n}$ \\
\hline LP2 Evap & $E_{F, \text { LP2Evap }}=E_{10}-E_{11}$ & $E_{P, L P 2 E v a p}=E_{49}-E_{48}$ & $\begin{array}{c}E_{D, L P 2 E v a p}= \\
E_{F, L P 2 E v a p}-E_{P, L P 2 E v a p}\end{array}$ \\
\hline LP2 Econ & $E_{F, L P 2 E c o n}=E_{11}-E_{12}$ & $E_{P, L P 2 E c o n}=E_{46}-E_{45}$ & $\begin{array}{c}E_{D, L P 2 E c o n}= \\
E_{F, L P 2 E c o n}-E_{P, L P 2 E c o n}\end{array}$ \\
\hline Preheater & $E_{F, P H}=E_{12}-E_{13}$ & $E_{P, P H}=E_{43}-E_{42}$ & $E_{D, P H}=E_{F, P H}-E_{P, P H}$ \\
\hline HP1 SH & $E_{F, H P 1 S H}=E_{15}-E_{16}$ & $E_{P, H P 1 S H}=E_{30}-E_{29}$ & $E_{D, H P 1 S H}=E_{F, H P 1 S H}-E_{P, H P 1 S H}$ \\
\hline HP1 Evap & $E_{F, H P 1 E v a p}=E_{16}-E_{17}$ & $E_{P, H P 1 \text { Evap }}=E_{29}-E_{28}$ & $\begin{array}{c}E_{D, H P 1 E v a p}= \\
E_{F, H P 1 E v a p}-E_{P, H P 1 E v a p}\end{array}$ \\
\hline HP1 Econ & $E_{F, H P 1 E c o n}=E_{17}-E_{18}$ & $E_{P, H P 1 E c o n}=E_{28}-E_{27}$ & $\begin{array}{c}E_{D, H P 1 E c o n}= \\
E_{F, H P 1 E c o n}-E_{P, H P 1 E c o n}\end{array}$ \\
\hline IP1 SH & $E_{F, I P 1 S H}=E_{18}-E_{19}$ & $E_{P, I P 1 S H}=E_{26}-E_{25}$ & $E_{D, I P 1 S H}=E_{F, I P 1 S H}-E_{P, I P 1 S H}$ \\
\hline IP1 Evap & $E_{F, I P 1 E v a p}=E_{19}-E_{20}$ & $E_{P, I P 1 \text { Evap }}=E_{25}-E_{24}$ & $E_{D, I P 1 \text { Evap }}=E_{F, I P 1 E v a p}-E_{P, I P 1 \text { Evap }}$ \\
\hline IP1 Econ & $E_{F, I P 1 E c o n}=E_{20}-E_{21}$ & $E_{P, I P 1 E c o n}=E_{24}-E_{23}$ & $E_{D, I P 1 E c o n}=E_{F, I P 1 E c o n}-E_{P, I P 1 E c o n}$ \\
\hline P1 & $\begin{array}{c}E_{F, P 1}=W_{P 1}= \\
\dot{m}\left(h_{22}-h_{21}\right) / n_{e l}\end{array}$ & $E_{P, P 1}=E_{22}-E_{21}$ & $E_{D, P 1}=E_{F, P 1}-E_{P, P 1}$ \\
\hline Solar field & $E_{F, S F}=Q_{\text {solar }} \times \Psi_{S} *$ & $E_{P, S F}=E_{14}-E_{22}$ & $E_{D_{, \prime S F}}=E_{F_{\text {, }} S F}-E_{P, S F}$ \\
\hline ST1 & $E_{F, S T 1}=E_{34}-E_{35}$ & $\begin{array}{l}E_{P, S T 1}=W_{S T 1}= \\
\dot{m}\left(h_{34}-h_{35}\right) * n_{e l}\end{array}$ & $E_{D, S T 1}=E_{F, S T 1}-E_{P, S T 1}$ \\
\hline ST2 & $E_{F, S T 2}=E_{36}-E_{37}$ & $\begin{array}{l}E_{P, S T 2}=W_{S T 2}= \\
\dot{m}\left(h_{36}-h_{37}\right) * n_{e l}\end{array}$ & $E_{D, S T 2}=E_{F, S T 2}-E_{P, S T 2}$ \\
\hline ST3 & $E_{F, S T 3}=E_{38}-E_{39}$ & $\begin{array}{l}E_{P, S T 3}=W_{S T 3}= \\
\dot{m}\left(h_{38}-h_{39}\right) * n_{e l}\end{array}$ & $E_{D, S T 3}=E_{F, S T 3}-E_{P, S T 3}$ \\
\hline ST4 & $E_{F, S T 4}=E_{39}-E_{40}$ & $\begin{array}{l}E_{P, S T 4}=W_{S T 4}= \\
\dot{m}\left(h_{39}-h_{40}\right) * n_{e l}\end{array}$ & $E_{D, S T 4}=E_{F, S T 4}-E_{P, S T 4}$ \\
\hline P2 & $\begin{array}{c}E_{F, P 2}=W_{P 2}= \\
\dot{m}\left(h_{45}-h_{44}\right) / n_{e l}\end{array}$ & $E_{P, P 2}=E_{45}-E_{44}$ & $E_{D, P 2}=E_{F, P 2}-E_{P, P 2}$ \\
\hline P3 & $\begin{array}{c}E_{F, P 3}=W_{P 3}= \\
\dot{m}\left(h_{53}-h_{47}\right) / n_{e l}\end{array}$ & $E_{P, P 3}=E_{53}-E_{47}$ & $E_{D, P 3}=E_{F, P 3}-E_{P, P 3}$ \\
\hline P4 & $\begin{array}{c}E_{F, P 4}=W_{P 4}= \\
\dot{m}\left(h_{61}-h_{60}\right) / n_{e l}\end{array}$ & $E_{P, P 4}=E_{61}-E_{60}$ & $E_{D, P 4}=E_{F, P 4}-E_{P, P 4}$ \\
\hline P5 & $\begin{array}{c}E_{F, P 5}=W_{P 5}= \\
\dot{m}\left(h_{42}-h_{41}\right) / n_{e l}\end{array}$ & $E_{P, P 5}=E_{42}-E_{41}$ & $E_{D, P 5}=E_{F, P 5}-E_{P, P 5}$ \\
\hline Cond & - & - & $E_{D, \text { Cond }}=E_{40}-E_{41}+E_{66}-E_{67}$ \\
\hline Cooling Tower & - & - & $\begin{array}{c}E_{D, C T}= \\
E_{67}+E_{69}+E_{70}-E_{66}-E_{68}-E_{71}\end{array}$ \\
\hline Deaerator & $\begin{array}{c}E_{F, \text { Deaerator }}= \\
m_{51} \times\left(\frac{E_{51}}{m_{51}}-\frac{E_{44}}{m_{44}}\right)\end{array}$ & $\begin{array}{c}E_{P, \text { Deaerator }}= \\
m_{43} \times\left(\frac{E_{44}}{m_{44}}-\frac{E_{43}}{m_{43}}\right)\end{array}$ & $\begin{array}{c}E_{D, \text { Deaerator }}= \\
E_{F, \text { Deaerator }}-E_{P, \text { Deaerator }}\end{array}$ \\
\hline
\end{tabular}


Table A2. Cont.

\begin{tabular}{cccc}
\hline Component & Exergy of the Fuel & Exergy of the Product & Exergy Destruction \\
\hline mixer 1 & $E_{F, M 1}=m_{26} \times\left(\frac{E_{26}}{m_{26}}-\frac{E_{58}}{m_{58}}\right)$ & $E_{P, M 1}=m_{57} \times\left(\frac{E_{58}}{m_{58}}-\frac{E_{57}}{m_{57}}\right)$ & $E_{D, M 1}=E_{F, M 1}-E_{P, M 1}$ \\
\hline mixer 2 & $E_{F, M 2}=m_{30} \times\left(\frac{E_{30}}{m_{30}}-\frac{E_{32}}{m_{32}}\right)$ & $E_{P, M 2}=m_{31} \times\left(\frac{E_{32}}{m_{32}}-\frac{E_{31}}{m_{31}}\right)$ & $E_{D, M 2}=E_{F, M 2}-E_{P, M 2}$ \\
\hline mixer 3 & $E_{F, M 3}=m_{33} \times\left(\frac{E_{33}}{m_{33}}-\frac{E_{34}}{m_{34}}\right)$ & $E_{P, M 3}=m_{65} \times\left(\frac{E_{34}}{m_{34}}-\frac{E_{65}}{m_{65}}\right)$ & $E_{D, M 3}=E_{F, M 3}-E_{P, M 3}$ \\
\hline mixer 4 & $E_{F, M 4}=m_{35} \times\left(\frac{E_{35}}{m_{35}}-\frac{E_{36}}{m_{36}}\right)$ & $E_{P, M 4}=m_{59} \times\left(\frac{E_{36}}{m_{36}}-\frac{E_{59}}{m_{59}}\right)$ & $E_{D, M 4}=E_{F, M 4}-E_{P, M 4}$ \\
\hline mixer 5 & $E_{F, M 5}=m_{50} \times\left(\frac{E_{50}}{m_{50}}-\frac{E_{38}}{m_{38}}\right)$ & $E_{P, M 5}=m_{37} \times\left(\frac{E_{38}}{m_{38}}-\frac{E_{37}}{m_{37}}\right)$ & $E_{D, M 5}=E_{F, M 5}-E_{P, M 5}$ \\
\hline Total & $E_{F, \text { tot }}=E_{52}+E_{72}$ & $E_{P, \text { tot }}=W_{\text {tot }}$ & $E_{D, \text { tot }}=$ \\
& $* \Psi_{S}=\left[1-\frac{4}{3}\left(\frac{T_{a}}{T_{s}}\right)+\frac{1}{3}\left(\frac{T_{a}}{T_{s}}\right)^{4}\right] ;$ with $T_{a}$ being the ambient temperature and $T_{S}=5600 \mathrm{~K}$.
\end{tabular}

Table A3. NGCC power plant with wet cooling system results at the stream level.

\begin{tabular}{|c|c|c|c|c|c|c|c|c|}
\hline Nr. & $\dot{E}_{P H}(\mathbf{M W})$ & $\dot{E}_{C H}(\mathbf{M W})$ & $\dot{E}_{T O T}(\mathbf{M W})$ & $c($ Cent/MJ) & $\dot{C}($ Cent/s) & $\dot{m}(\mathrm{~kg} / \mathrm{s})$ & $T\left({ }^{\circ} \mathrm{C}\right)$ & $p$ (bar) \\
\hline 1 & 0.000 & 1.06 & 1.06 & 0.00 & 0.00 & 679.09 & 15.00 & 1.01 \\
\hline 2 & 258.135 & 1.06 & 259.19 & 1.60 & 414.15 & 679.09 & 398.97 & 17.00 \\
\hline 3 & 792.079 & 5.40 & 797.47 & 1.28 & 1017.96 & 693.75 & 1239.86 & 16.50 \\
\hline 4 & 204.133 & 5.40 & 209.53 & 1.28 & 267.46 & 693.75 & 582.98 & 1.06 \\
\hline 5 & 85.331 & 2.26 & 87.59 & 1.28 & 111.80 & 290.00 & 582.98 & 1.06 \\
\hline 6 & 46.641 & 2.26 & 48.90 & 1.28 & 62.42 & 290.00 & 397.16 & 1.05 \\
\hline 7 & 118.803 & 3.14 & 121.94 & 1.28 & 155.66 & 403.75 & 582.98 & 1.06 \\
\hline 8 & 89.523 & 3.14 & 92.66 & 1.28 & 118.28 & 403.75 & 486.71 & 1.05 \\
\hline 9 & 135.732 & 5.40 & 141.13 & 1.28 & 180.70 & 693.75 & 449.51 & 1.05 \\
\hline 10 & 87.461 & 5.40 & 92.86 & 1.28 & 118.89 & 693.75 & 341.49 & 1.05 \\
\hline 11 & 55.054 & 5.40 & 60.45 & 1.28 & 77.40 & 693.75 & 256.63 & 1.04 \\
\hline 12 & 54.527 & 5.40 & 59.92 & 1.28 & 76.72 & 693.75 & 255.92 & 1.04 \\
\hline 13 & 47.798 & 5.40 & 53.19 & 1.28 & 68.11 & 693.75 & 236.74 & 1.03 \\
\hline 14 & 46.321 & 5.40 & 51.72 & 1.28 & 66.22 & 693.75 & 233.07 & 1.03 \\
\hline 15 & 44.736 & 5.40 & 50.13 & 1.28 & 64.19 & 693.75 & 229.04 & 1.02 \\
\hline 16 & 25.269 & 5.40 & 30.66 & 1.28 & 39.26 & 693.75 & 162.21 & 1.02 \\
\hline 17 & 11.878 & 5.40 & 17.27 & 1.28 & 22.12 & 693.75 & 100.15 & 1.01 \\
\hline 18 & 80.543 & 0.18 & 80.73 & 1.62 & 131.14 & 73.31 & 330.98 & 130.21 \\
\hline 19 & 116.512 & 0.18 & 116.69 & 1.61 & 187.74 & 73.31 & 562.98 & 125.00 \\
\hline 20 & 82.373 & 0.18 & 82.56 & 1.61 & 132.82 & 73.31 & 322.63 & 25.00 \\
\hline 21 & 90.404 & 0.20 & 90.61 & 1.64 & 148.76 & 81.15 & 314.77 & 25.00 \\
\hline 22 & 117.165 & 0.20 & 117.37 & 1.61 & 189.10 & 81.15 & 562.98 & 25.00 \\
\hline 23 & 76.987 & 0.20 & 77.19 & 1.61 & 124.37 & 81.15 & 330.82 & 5.00 \\
\hline 24 & 95.461 & 0.26 & 95.72 & 1.68 & 160.97 & 103.59 & 305.20 & 5.00 \\
\hline 25 & 13.574 & 0.26 & 13.83 & 1.68 & 23.26 & 103.59 & 32.87 & 0.05 \\
\hline 26 & 0.221 & 0.26 & 0.48 & 1.68 & 0.81 & 103.59 & 32.87 & 0.05 \\
\hline 27 & 0.262 & 0.26 & 0.52 & 1.94 & 1.01 & 103.59 & 32.89 & 4.00 \\
\hline 28 & 9.019 & 0.26 & 9.28 & 2.24 & 20.74 & 103.59 & 138.00 & 3.80 \\
\hline 29 & 9.597 & 0.26 & 9.86 & 2.31 & 22.79 & 104.37 & 141.77 & 3.80 \\
\hline 30 & 7.462 & 0.20 & 7.66 & 2.31 & 17.72 & 81.15 & 141.77 & 3.80 \\
\hline 31 & 6.741 & 0.18 & 6.92 & 2.31 & 16.01 & 73.31 & 141.77 & 3.80 \\
\hline 32 & 2.135 & 0.06 & 2.19 & 2.31 & 5.07 & 23.21 & 141.77 & 3.80 \\
\hline 33 & 2.138 & 0.06 & 2.20 & 2.37 & 5.20 & 23.21 & 141.79 & 5.05 \\
\hline 34 & 18.242 & 0.06 & 18.30 & 1.92 & 35.20 & 23.21 & 152.21 & 5.05 \\
\hline 35 & 0.612 & 0.00 & 0.61 & 1.92 & 1.18 & 0.78 & 152.21 & 5.05 \\
\hline 36 & 17.630 & 0.06 & 17.69 & 1.92 & 34.02 & 22.44 & 152.21 & 5.05 \\
\hline 37 & 18.712 & 0.06 & 18.77 & 1.95 & 36.60 & 22.44 & 213.07 & 5.00 \\
\hline 38 & 0.720 & 0.02 & 0.74 & 2.31 & 1.71 & 7.83 & 141.77 & 3.80 \\
\hline 39 & 0.740 & 0.02 & 0.76 & 2.53 & 1.92 & 7.83 & 142.05 & 26.36 \\
\hline 40 & 1.749 & 0.02 & 1.77 & 2.26 & 3.99 & 7.83 & 221.70 & 26.31 \\
\hline 41 & 7.891 & 0.02 & 7.91 & 1.90 & 15.05 & 7.83 & 226.70 & 26.31 \\
\hline 42 & 8.078 & 0.02 & 8.10 & 1.97 & 15.94 & 7.83 & 246.63 & 25.00 \\
\hline 43 & 7.823 & 0.18 & 8.01 & 2.43 & 19.46 & 73.31 & 143.41 & 137.06 \\
\hline 44 & 35.867 & 0.18 & 36.05 & 1.77 & 63.76 & 73.31 & 325.98 & 130.21 \\
\hline 45 & 0.361 & 24.32 & 24.68 & 6.18 & 152.47 & 9736.49 & 17.26 & 1.01 \\
\hline
\end{tabular}


Table A3. Cont.

\begin{tabular}{ccccccccc}
\hline Nr. & $\dot{E}_{\boldsymbol{P H}}(\mathbf{M W})$ & $\dot{E}_{\boldsymbol{C H}}(\mathbf{M W})$ & $\dot{E}_{\boldsymbol{T O T}}(\mathbf{M W})$ & $c($ Cent/MJ) & $\dot{\boldsymbol{C}}(\mathbf{C e n t} / \mathbf{s})$ & $\dot{m}(\mathbf{k g} / \mathbf{s})$ & $\boldsymbol{T}\left({ }^{\circ} \mathbf{C}\right)$ & $p(\mathbf{b a r})$ \\
\hline 46 & 4.307 & 24.32 & 28.63 & 6.18 & 176.85 & 9736.49 & 22.87 & 1.01 \\
47 & 0.001 & 0.06 & 0.06 & 6.18 & 0.40 & 25.61 & 17.26 & 1.01 \\
48 & 0.000 & 0.26 & 0.26 & 0.00 & 0.00 & 102.82 & 15.00 & 1.01 \\
49 & 0.000 & 13.80 & 13.80 & 0.00 & 0.00 & 4868.20 & 15.00 & 1.01 \\
50 & 1.061 & 7.15 & 8.21 & 3.20 & 26.29 & 4945.41 & 21.46 & 1.01 \\
51 & 6.180 & 755.48 & 761.66 & 0.76 & 578.48 & 14.66 & 25.00 & 17.00 \\
\hline
\end{tabular}

Table A4. NGCC power plant with dry cooling system results at the stream level.

\begin{tabular}{|c|c|c|c|c|c|c|c|c|}
\hline Nr. & $\dot{E}_{P H}(\mathbf{M W})$ & $\dot{E}_{C H}(\mathbf{M W})$ & $\dot{E}_{T O T}(\mathbf{M W})$ & $c($ Cent/MJ) & $\dot{C}($ Cent $/ \mathrm{s})$ & $\dot{m}(\mathrm{~kg} / \mathrm{s})$ & $T\left({ }^{\circ} \mathrm{C}\right)$ & $p$ (bar) \\
\hline 1 & 0.000 & 1.07 & 1.07 & 0.00 & 0.00 & 690.55 & 15.00 & 1.01 \\
\hline 2 & 262.489 & 1.07 & 263.56 & 1.59 & 418.28 & 690.55 & 398.97 & 17.00 \\
\hline 3 & 805.440 & 5.49 & 810.93 & 1.27 & 1031.54 & 705.46 & 1239.86 & 16.50 \\
\hline 4 & 207.577 & 5.49 & 213.06 & 1.27 & 271.03 & 705.46 & 582.98 & 1.06 \\
\hline 5 & 85.331 & 2.26 & 87.59 & 1.27 & 111.41 & 290.00 & 582.98 & 1.06 \\
\hline 6 & 46.045 & 2.26 & 48.30 & 1.27 & 61.44 & 290.00 & 393.95 & 1.05 \\
\hline 7 & 122.246 & 3.23 & 125.48 & 1.27 & 159.61 & 415.46 & 582.98 & 1.06 \\
\hline 8 & 92.458 & 3.23 & 95.69 & 1.27 & 121.72 & 415.46 & 487.86 & 1.05 \\
\hline 9 & 138.022 & 5.49 & 143.51 & 1.28 & 183.16 & 705.46 & 449.51 & 1.05 \\
\hline 10 & 88.936 & 5.49 & 94.42 & 1.28 & 120.51 & 705.46 & 341.49 & 1.05 \\
\hline 11 & 55.982 & 5.49 & 61.47 & 1.28 & 78.45 & 705.46 & 256.63 & 1.04 \\
\hline 12 & 55.446 & 5.49 & 60.93 & 1.28 & 77.77 & 705.46 & 255.92 & 1.04 \\
\hline 13 & 48.605 & 5.49 & 54.09 & 1.28 & 69.04 & 705.46 & 236.74 & 1.03 \\
\hline 14 & 47.102 & 5.49 & 52.59 & 1.28 & 67.12 & 705.46 & 233.07 & 1.03 \\
\hline 15 & 45.491 & 5.49 & 50.98 & 1.28 & 65.06 & 705.46 & 229.04 & 1.02 \\
\hline 16 & 25.695 & 5.49 & 31.18 & 1.28 & 39.80 & 705.46 & 162.21 & 1.02 \\
\hline 17 & 12.079 & 5.49 & 17.56 & 1.28 & 22.42 & 705.46 & 100.15 & 1.01 \\
\hline 18 & 81.902 & 0.19 & 82.09 & 1.62 & 132.77 & 74.55 & 330.98 & 130.21 \\
\hline 19 & 118.477 & 0.19 & 118.66 & 1.60 & 189.86 & 74.55 & 562.98 & 125.00 \\
\hline 20 & 83.762 & 0.19 & 83.95 & 1.60 & 134.32 & 74.55 & 322.63 & 25.00 \\
\hline 21 & 91.929 & 0.21 & 92.13 & 1.63 & 150.44 & 82.52 & 314.77 & 25.00 \\
\hline 22 & 119.141 & 0.21 & 119.35 & 1.60 & 191.49 & 82.52 & 562.98 & 25.00 \\
\hline 23 & 78.286 & 0.21 & 78.49 & 1.60 & 125.94 & 82.52 & 330.82 & 5.00 \\
\hline 24 & 97.071 & 0.26 & 97.33 & 1.67 & 162.96 & 105.33 & 305.20 & 5.00 \\
\hline 25 & 13.802 & 0.26 & 14.07 & 1.67 & 23.55 & 105.33 & 32.87 & 0.05 \\
\hline 26 & 0.224 & 0.26 & 0.49 & 1.67 & 0.82 & 105.33 & 32.87 & 0.05 \\
\hline 27 & 0.266 & 0.26 & 0.53 & 1.93 & 1.02 & 105.33 & 32.89 & 4.00 \\
\hline 28 & 9.171 & 0.26 & 9.43 & 2.23 & 21.00 & 105.33 & 138.00 & 3.80 \\
\hline 29 & 9.758 & 0.27 & 10.02 & 2.30 & 23.05 & 106.13 & 141.77 & 3.80 \\
\hline 30 & 7.588 & 0.21 & 7.79 & 2.30 & 17.92 & 82.52 & 141.77 & 3.80 \\
\hline 31 & 6.855 & 0.19 & 7.04 & 2.30 & 16.19 & 74.55 & 141.77 & 3.80 \\
\hline 32 & 2.171 & 0.06 & 2.23 & 2.30 & 5.13 & 23.61 & 141.77 & 3.80 \\
\hline 33 & 2.174 & 0.06 & 2.23 & 2.35 & 5.25 & 23.61 & 141.79 & 5.05 \\
\hline 34 & 18.549 & 0.06 & 18.61 & 1.91 & 35.61 & 23.61 & 152.21 & 5.05 \\
\hline 35 & 0.622 & 0.00 & 0.62 & 1.91 & 1.19 & 0.79 & 152.21 & 5.05 \\
\hline 36 & 17.928 & 0.06 & 17.98 & 1.91 & 34.42 & 22.81 & 152.21 & 5.05 \\
\hline 37 & 19.027 & 0.06 & 19.08 & 1.94 & 37.02 & 22.81 & 213.07 & 5.00 \\
\hline 38 & 0.733 & 0.02 & 0.75 & 2.30 & 1.73 & 7.97 & 141.77 & 3.80 \\
\hline 39 & 0.753 & 0.02 & 0.77 & 2.51 & 1.94 & 7.97 & 142.05 & 26.36 \\
\hline 40 & 1.779 & 0.02 & 1.80 & 2.24 & 4.04 & 7.97 & 221.70 & 26.31 \\
\hline 41 & 8.025 & 0.02 & 8.04 & 1.89 & 15.22 & 7.97 & 226.70 & 26.31 \\
\hline 42 & 8.215 & 0.02 & 8.23 & 1.96 & 16.12 & 7.97 & 246.63 & 25.00 \\
\hline 43 & 7.955 & 0.19 & 8.14 & 2.42 & 19.67 & 74.55 & 143.41 & 137.06 \\
\hline 44 & 36.472 & 0.19 & 36.66 & 1.76 & 64.53 & 74.55 & 325.98 & 130.21 \\
\hline 45 & 0.000 & 85.80 & 85.80 & 0.00 & 0.00 & 30273.16 & 15.00 & 1.01 \\
\hline 46 & 3.214 & 85.80 & 89.01 & 0.53 & 46.94 & 30273.16 & 22.87 & 1.01 \\
\hline 47 & 6.284 & 768.23 & 774.51 & 0.76 & 588.24 & 14.91 & 25.00 & 17.00 \\
\hline
\end{tabular}

Table A5. ISCC power plant with wet cooling system results at the stream level.

\begin{tabular}{ccccccccc}
\hline Nr. & $\dot{E}_{P H}(\mathbf{M W})$ & $\dot{E}_{C H}(\mathbf{M W})$ & $\dot{E}_{T O T}(\mathbf{M W})$ & $c($ Cent/MJ) & $\dot{\boldsymbol{C}}(\mathbf{C e n t} / \mathbf{s})$ & $\dot{m}(\mathbf{k g} / \mathbf{s})$ & $\boldsymbol{T}\left({ }^{\circ} \mathbf{C}\right)$ & $p$ (bar) \\
\hline 1 & 0.000 & 0.77 & 1.29 & 0.00 & 0.00 & 533.39 & 33.40 & 1.01 \\
2 & 203.878 & 0.77 & 204.65 & 1.52 & 312.04 & 533.39 & 412.78 & 15.00 \\
3 & 619.519 & 4.19 & 623.71 & 1.24 & 776.47 & 544.75 & 1231.88 & 14.50 \\
\hline
\end{tabular}


Table A5. Cont.

\begin{tabular}{|c|c|c|c|c|c|c|c|c|}
\hline Nr. & $\dot{E}_{P H}(\mathbf{M W})$ & $\dot{E}_{C H}(\mathbf{M W})$ & $\dot{E}_{T O T}(\mathbf{M W})$ & $c($ Cent/MJ) & $\dot{C}($ Cent/s) & $\dot{m}(\mathrm{~kg} / \mathrm{s})$ & $T\left({ }^{\circ} \mathrm{C}\right)$ & $p$ (bar) \\
\hline 4 & 171.565 & 4.19 & 175.76 & 1.24 & 218.80 & 544.75 & 604.99 & 1.03 \\
\hline 5 & 103.974 & 4.19 & 108.17 & 1.24 & 134.66 & 544.75 & 439.19 & 1.02 \\
\hline 6 & 69.503 & 4.19 & 73.70 & 1.24 & 91.75 & 544.75 & 340.68 & 1.02 \\
\hline 7 & 67.692 & 4.19 & 71.88 & 1.24 & 89.49 & 544.75 & 335.35 & 1.02 \\
\hline 8 & 52.306 & 4.19 & 56.50 & 1.24 & 70.34 & 544.75 & 285.61 & 1.02 \\
\hline 9 & 45.039 & 4.19 & 49.23 & 1.24 & 61.29 & 544.75 & 260.06 & 1.02 \\
\hline 10 & 35.797 & 4.19 & 39.99 & 1.24 & 49.78 & 544.75 & 225.39 & 1.02 \\
\hline 11 & 21.034 & 4.19 & 25.23 & 1.24 & 31.41 & 544.75 & 159.84 & 1.02 \\
\hline 12 & 20.390 & 4.19 & 24.58 & 1.24 & 30.60 & 544.75 & 157.01 & 1.02 \\
\hline 13 & 5.482 & 4.19 & 9.67 & 1.24 & 12.04 & 544.75 & 46.10 & 1.01 \\
\hline 14 & 344.442 & 3.88 & 344.44 & 0.96 & 330.35 & 1047.71 & 395.00 & 35.00 \\
\hline 15 & 344.442 & 3.88 & 344.44 & 0.96 & 330.35 & 1047.71 & 395.00 & 35.00 \\
\hline 16 & 329.205 & 3.88 & 329.20 & 0.96 & 315.74 & 1047.71 & 385.48 & 35.00 \\
\hline 17 & 262.472 & 3.88 & 262.47 & 0.96 & 251.73 & 1047.71 & 340.83 & 35.00 \\
\hline 18 & 226.053 & 3.88 & 226.05 & 0.96 & 216.80 & 1047.71 & 314.10 & 35.00 \\
\hline 19 & 224.367 & 3.88 & 224.37 & 0.96 & 215.19 & 1047.71 & 312.82 & 34.99 \\
\hline 20 & 204.434 & 3.88 & 204.43 & 0.96 & 196.07 & 1047.71 & 297.28 & 34.99 \\
\hline 21 & 199.482 & 3.88 & 199.48 & 0.96 & 191.32 & 1047.71 & 293.32 & 34.99 \\
\hline 22 & 201.636 & 3.88 & 201.64 & 0.98 & 197.85 & 1047.71 & 294.31 & 50.00 \\
\hline 23 & 2.341 & 0.05 & 2.40 & 2.17 & 5.20 & 21.87 & 150.44 & 40.00 \\
\hline 24 & 6.047 & 0.05 & 6.10 & 1.67 & 10.19 & 21.87 & 247.28 & 39.95 \\
\hline 25 & 23.040 & 0.05 & 23.10 & 1.35 & 31.11 & 21.87 & 250.28 & 39.95 \\
\hline 26 & 24.521 & 0.05 & 24.58 & 1.35 & 33.18 & 21.87 & 294.10 & 39.90 \\
\hline 27 & 15.797 & 0.24 & 16.04 & 2.11 & 33.83 & 97.45 & 181.89 & 130.00 \\
\hline 28 & 45.964 & 0.24 & 46.21 & 1.53 & 70.84 & 97.45 & 320.83 & 129.95 \\
\hline 29 & 107.070 & 0.24 & 107.31 & 1.35 & 144.92 & 97.45 & 330.83 & 129.95 \\
\hline 30 & 120.980 & 0.24 & 121.22 & 1.34 & 162.92 & 97.45 & 375.00 & 129.90 \\
\hline 31 & 49.738 & 0.11 & 49.85 & 1.58 & 78.65 & 45.26 & 330.68 & 129.70 \\
\hline 32 & 170.563 & 0.36 & 170.92 & 1.41 & 241.57 & 142.71 & 357.15 & 129.70 \\
\hline 33 & 234.789 & 0.36 & 235.15 & 1.43 & 336.65 & 142.71 & 594.99 & 129.65 \\
\hline 34 & 236.509 & 0.38 & 236.89 & 1.45 & 344.45 & 153.79 & 532.00 & 129.65 \\
\hline 35 & 185.785 & 0.38 & 186.17 & 1.45 & 270.70 & 153.79 & 358.10 & 39.75 \\
\hline 36 & 219.830 & 0.46 & 220.29 & 1.45 & 320.03 & 183.23 & 351.21 & 39.75 \\
\hline 37 & 139.923 & 0.46 & 140.38 & 1.45 & 203.95 & 183.23 & 150.30 & 4.80 \\
\hline 38 & 145.036 & 0.47 & 145.51 & 1.47 & 213.38 & 189.79 & 150.30 & 4.80 \\
\hline 39 & 96.766 & 0.47 & 97.24 & 1.47 & 142.59 & 189.79 & 99.60 & 1.00 \\
\hline 40 & 22.423 & 0.47 & 22.90 & 1.47 & 33.58 & 189.79 & 32.87 & 0.05 \\
\hline 41 & 0.404 & 0.47 & 0.88 & 1.47 & 1.29 & 189.79 & 32.87 & 0.05 \\
\hline 42 & 0.491 & 0.47 & 0.97 & 1.65 & 1.60 & 189.79 & 32.91 & 4.55 \\
\hline 43 & 11.772 & 0.47 & 12.25 & 2.07 & 25.33 & 189.79 & 117.01 & 4.50 \\
\hline 44 & 20.199 & 0.50 & 20.70 & 2.11 & 43.73 & 201.58 & 147.91 & 4.50 \\
\hline 45 & 20.212 & 0.50 & 20.72 & 2.12 & 43.86 & 201.58 & 147.92 & 5.05 \\
\hline 46 & 20.740 & 0.50 & 21.24 & 2.12 & 45.11 & 201.58 & 149.84 & 5.00 \\
\hline 47 & 18.852 & 0.46 & 19.31 & 2.12 & 41.00 & 183.23 & 149.84 & 5.00 \\
\hline 48 & 1.888 & 0.05 & 1.93 & 2.12 & 4.11 & 18.35 & 149.84 & 5.00 \\
\hline 49 & 14.392 & 0.05 & 14.44 & 1.83 & 26.37 & 18.35 & 151.84 & 5.00 \\
\hline 50 & 5.147 & 0.02 & 5.16 & 1.83 & 9.43 & 6.56 & 151.84 & 5.00 \\
\hline 51 & 9.245 & 0.03 & 9.27 & 1.83 & 16.94 & 11.79 & 151.84 & 5.00 \\
\hline 52 & - & - & - & - & - & 11.79 & 149.90 & 4.50 \\
\hline 53 & 19.606 & 0.46 & 20.06 & 2.17 & 43.54 & 183.23 & 150.44 & 40.00 \\
\hline 54 & 17.266 & 0.40 & 17.67 & 2.17 & 38.35 & 161.35 & 150.44 & 40.00 \\
\hline 55 & 24.374 & 0.40 & 24.78 & 2.03 & 50.39 & 161.35 & 180.06 & 39.80 \\
\hline 56 & 1.143 & 0.02 & 1.16 & 2.03 & 2.36 & 7.56 & 180.06 & 39.80 \\
\hline 57 & 7.965 & 0.02 & 7.98 & 1.68 & 13.40 & 7.56 & 250.06 & 39.80 \\
\hline 58 & 32.462 & 0.07 & 32.54 & 1.43 & 46.58 & 29.44 & 281.44 & 39.80 \\
\hline 59 & 34.079 & 0.07 & 34.15 & 1.44 & 49.34 & 29.44 & 320.68 & 39.75 \\
\hline 60 & 23.231 & 0.38 & 23.62 & 2.03 & 48.03 & 153.79 & 180.06 & 39.80 \\
\hline 61 & 24.930 & 0.38 & 25.31 & 2.11 & 53.39 & 153.79 & 181.89 & 130.00 \\
\hline 62 & 9.133 & 0.14 & 9.27 & 2.11 & 19.56 & 56.34 & 181.89 & 130.00 \\
\hline 63 & 22.343 & 0.14 & 22.48 & 1.76 & 39.66 & 56.34 & 295.35 & 129.70 \\
\hline 64 & 17.949 & 0.11 & 18.06 & 1.76 & 31.86 & 45.26 & 295.35 & 129.70 \\
\hline 65 & 4.394 & 0.03 & 4.42 & 1.76 & 7.80 & 11.08 & 295.35 & 129.70 \\
\hline 66 & 6.189 & 40.48 & 46.67 & 2.75 & 128.42 & 16207.28 & 22.31 & 1.01 \\
\hline 67 & 18.858 & 40.48 & 59.34 & 2.75 & 163.28 & 16207.28 & 27.87 & 0.96 \\
\hline 68 & 0.022 & 0.15 & 0.17 & 2.75 & 0.46 & 58.24 & 22.31 & 1.01 \\
\hline 69 & 0.551 & 0.58 & 1.13 & 0.00 & 0.00 & 233.62 & 33.40 & 1.01 \\
\hline 70 & 4.589 & 22.97 & 27.56 & 0.00 & 0.00 & 8103.56 & 33.40 & 1.01 \\
\hline 71 & 6.476 & 12.02 & 18.49 & 2.01 & 37.14 & 8278.93 & 26.49 & 1.01 \\
\hline 72 & 4.578 & 585.66 & 590.23 & 0.76 & 448.28 & 11.36 & 25.00 & 15.00 \\
\hline
\end{tabular}


Table A6. ISCC power plant with dry cooling system results at the stream level.

\begin{tabular}{|c|c|c|c|c|c|c|c|c|}
\hline Nr. & $\dot{E}_{P H}(\mathrm{MW})$ & $\dot{E}_{C H}(\mathrm{MW})$ & $\dot{E}_{T O T}(\mathrm{MW})$ & $c($ Cent/MJ) & $\dot{C}($ Cent/s $)$ & $\dot{m}(\mathrm{~kg} / \mathrm{s})$ & $T\left({ }^{\circ} \mathrm{C}\right)$ & $p$ (bar) \\
\hline 1 & 0.000 & 0.83 & 1.38 & 0.00 & 0.00 & 437.14 & 33.40 & 1.01 \\
\hline 2 & 234.268 & 0.83 & 235.10 & 1.51 & 355.34 & 437.14 & 437.15 & 17.00 \\
\hline 3 & 685.155 & 4.51 & 689.66 & 1.24 & 855.32 & 585.91 & 1251.70 & 16.50 \\
\hline 4 & 179.669 & 4.51 & 184.18 & 1.24 & 228.42 & 585.91 & 594.64 & 1.03 \\
\hline 5 & 112.354 & 4.51 & 116.86 & 1.24 & 144.93 & 585.91 & 440.50 & 1.02 \\
\hline 6 & 74.754 & 4.51 & 79.26 & 1.24 & 98.30 & 585.91 & 340.68 & 1.02 \\
\hline 7 & 72.818 & 4.51 & 77.33 & 1.24 & 95.90 & 585.91 & 335.39 & 1.02 \\
\hline 8 & 56.706 & 4.51 & 61.21 & 1.24 & 75.92 & 585.91 & 287.04 & 1.02 \\
\hline 9 & 48.442 & 4.51 & 52.95 & 1.24 & 65.67 & 585.91 & 260.06 & 1.02 \\
\hline 10 & 38.969 & 4.51 & 43.48 & 1.24 & 53.92 & 585.91 & 227.12 & 1.02 \\
\hline 11 & 22.623 & 4.51 & 27.13 & 1.24 & 33.65 & 585.91 & 159.84 & 1.02 \\
\hline 12 & 21.957 & 4.51 & 26.47 & 1.24 & 32.82 & 585.91 & 157.13 & 1.02 \\
\hline 13 & 7.791 & 4.51 & 12.30 & 1.24 & 15.25 & 585.91 & 67.07 & 1.01 \\
\hline 14 & 344.442 & 3.88 & 344.44 & 0.95 & 326.08 & 1047.71 & 395.00 & 35.00 \\
\hline 15 & 344.442 & 3.88 & 344.44 & 0.95 & 326.08 & 1047.71 & 395.00 & 35.00 \\
\hline 16 & 329.205 & 3.88 & 329.20 & 0.95 & 311.66 & 1047.71 & 385.48 & 35.00 \\
\hline 17 & 262.472 & 3.88 & 262.47 & 0.95 & 248.48 & 1047.71 & 340.83 & 35.00 \\
\hline 18 & 226.053 & 3.88 & 226.05 & 0.95 & 214.00 & 1047.71 & 314.10 & 35.00 \\
\hline 19 & 224.367 & 3.88 & 224.37 & 0.95 & 212.41 & 1047.71 & 312.82 & 34.99 \\
\hline 20 & 204.434 & 3.88 & 204.43 & 0.95 & 193.54 & 1047.71 & 297.28 & 34.99 \\
\hline 21 & 199.482 & 3.88 & 199.48 & 0.95 & 188.85 & 1047.71 & 293.32 & 34.99 \\
\hline 22 & 201.636 & 3.88 & 201.64 & 0.97 & 195.27 & 1047.71 & 294.31 & 50.00 \\
\hline 23 & 2.341 & 0.05 & 2.40 & 2.09 & 5.00 & 21.87 & 150.44 & 40.00 \\
\hline 24 & 6.047 & 0.05 & 6.10 & 1.63 & 9.92 & 21.87 & 247.28 & 39.95 \\
\hline 25 & 23.040 & 0.05 & 23.10 & 1.32 & 30.57 & 21.87 & 250.28 & 39.95 \\
\hline 26 & 24.521 & 0.05 & 24.58 & 1.33 & 32.61 & 21.87 & 294.10 & 39.90 \\
\hline 27 & 15.797 & 0.24 & 16.04 & 2.05 & 32.86 & 97.45 & 181.89 & 130.00 \\
\hline 28 & 45.964 & 0.24 & 46.21 & 1.50 & 69.39 & 97.45 & 320.83 & 129.95 \\
\hline 29 & 107.070 & 0.24 & 107.31 & 1.33 & 142.52 & 97.45 & 330.83 & 129.95 \\
\hline 30 & 120.980 & 0.24 & 121.22 & 1.32 & 160.29 & 97.45 & 375.00 & 129.90 \\
\hline 31 & 54.220 & 0.12 & 54.34 & 1.56 & 84.91 & 49.34 & 330.68 & 129.70 \\
\hline 32 & 175.037 & 0.37 & 175.40 & 1.40 & 245.20 & 146.79 & 356.20 & 129.70 \\
\hline 33 & 238.907 & 0.37 & 239.27 & 1.42 & 339.30 & 146.79 & 584.64 & 129.65 \\
\hline 34 & 240.434 & 0.39 & 240.82 & 1.44 & 345.92 & 156.34 & 532.00 & 129.65 \\
\hline 35 & 188.868 & 0.39 & 189.26 & 1.44 & 271.85 & 156.34 & 358.10 & 39.75 \\
\hline 36 & 224.101 & 0.47 & 224.57 & 1.44 & 322.39 & 186.81 & 351.82 & 39.75 \\
\hline 37 & 142.646 & 0.47 & 143.11 & 1.44 & 205.45 & 186.81 & 150.30 & 4.80 \\
\hline 38 & 149.034 & 0.49 & 149.52 & 1.45 & 217.09 & 195.00 & 150.30 & 4.80 \\
\hline 39 & 99.432 & 0.49 & 99.92 & 1.45 & 145.07 & 195.00 & 99.60 & 1.00 \\
\hline 40 & 43.316 & 0.49 & 43.80 & 1.45 & 63.60 & 195.00 & 49.42 & 0.12 \\
\hline 41 & 1.418 & 0.49 & 1.90 & 1.45 & 2.77 & 195.00 & 48.04 & 0.11 \\
\hline 42 & 1.508 & 0.49 & 1.99 & 1.54 & 3.06 & 195.00 & 48.08 & 4.55 \\
\hline 43 & 12.123 & 0.49 & 12.61 & 1.94 & 24.48 & 195.00 & 117.13 & 4.50 \\
\hline 44 & 20.749 & 0.52 & 21.27 & 2.03 & 43.09 & 207.06 & 147.91 & 4.50 \\
\hline 45 & 20.763 & 0.52 & 21.28 & 2.03 & 43.22 & 207.06 & 147.92 & 5.05 \\
\hline 46 & 21.305 & 0.52 & 21.82 & 2.04 & 44.50 & 207.06 & 149.84 & 5.00 \\
\hline 47 & 19.220 & 0.47 & 19.69 & 2.04 & 40.14 & 186.81 & 149.84 & 5.00 \\
\hline 48 & 2.084 & 0.05 & 2.13 & 2.04 & 4.35 & 20.26 & 149.84 & 5.00 \\
\hline 49 & 15.890 & 0.05 & 15.94 & 1.80 & 28.76 & 20.26 & 151.84 & 5.00 \\
\hline 50 & 6.430 & 0.02 & 6.45 & 1.80 & 11.64 & 8.20 & 151.84 & 5.00 \\
\hline 51 & 9.460 & 0.03 & 9.49 & 1.80 & 17.12 & 12.06 & 151.84 & 5.00 \\
\hline 52 & - & - & - & - & - & 12.06 & 149.90 & 4.50 \\
\hline 53 & 19.989 & 0.47 & 20.46 & 2.09 & 42.69 & 186.81 & 150.44 & 40.00 \\
\hline 54 & 17.649 & 0.41 & 18.06 & 2.09 & 37.69 & 164.93 & 150.44 & 40.00 \\
\hline 55 & 24.914 & 0.41 & 25.33 & 1.97 & 49.98 & 164.93 & 180.06 & 39.80 \\
\hline 56 & 1.298 & 0.02 & 1.32 & 1.97 & 2.60 & 8.59 & 180.06 & 39.80 \\
\hline 57 & 9.046 & 0.02 & 9.07 & 1.65 & 15.00 & 8.59 & 250.06 & 39.80 \\
\hline 58 & 33.542 & 0.08 & 33.62 & 1.42 & 47.62 & 30.46 & 280.26 & 39.80 \\
\hline 59 & 35.267 & 0.08 & 35.34 & 1.43 & 50.54 & 30.46 & 320.68 & 39.75 \\
\hline 60 & 23.616 & 0.39 & 24.01 & 1.97 & 47.37 & 156.34 & 180.06 & 39.80 \\
\hline 61 & 25.344 & 0.39 & 25.73 & 2.05 & 52.72 & 156.34 & 181.89 & 130.00 \\
\hline 62 & 9.547 & 0.15 & 9.69 & 2.05 & 19.86 & 58.89 & 181.89 & 130.00 \\
\hline 63 & 23.361 & 0.15 & 23.51 & 1.74 & 40.81 & 58.89 & 295.39 & 129.70 \\
\hline 64 & 19.571 & 0.12 & 19.69 & 1.74 & 34.19 & 49.34 & 295.39 & 129.70 \\
\hline 65 & 3.790 & 0.02 & 3.81 & 1.74 & 6.62 & 9.55 & 295.39 & 129.70 \\
\hline 66 & 23.541 & 117.81 & 141.35 & 0.00 & 0.00 & 41567.60 & 33.40 & 1.01 \\
\hline 67 & 53.564 & 117.81 & 171.37 & 0.57 & 98.52 & 41567.60 & 43.04 & 1.01 \\
\hline 68 & 5.153 & 629.90 & 635.05 & 0.76 & 482.32 & 12.22 & 25.00 & 17.00 \\
\hline
\end{tabular}


Table A7. NGCC power plant with wet cooling results at the component level.

\begin{tabular}{|c|c|c|c|c|c|c|c|c|c|c|c|c|}
\hline Component & $\dot{E}_{F, k}(\mathbf{M W})$ & $\dot{E}_{P, k}(\mathrm{MW})$ & $\dot{E}_{D, k}(\mathrm{MW})$ & $y_{D, k}(\%)$ & $y_{D, k} *(\%)$ & $\varepsilon_{k}(\%)$ & $c_{F, k}($ Cent/MJ $)$ & $c_{P, k}($ Cent $/ \mathbf{M J})$ & $\dot{C}_{D, k}($ Cent $/ \mathrm{s})$ & $Z_{K}($ Cent $/ \mathbf{s})$ & $f_{K}(\%)$ & $r_{K}(\%)$ \\
\hline Compressor & 269.93 & 258.13 & 11.80 & 1.55 & 3.76 & 95.63 & 1.40 & 1.60 & 16.55 & 35.45 & 68.17 & 14.29 \\
\hline CC & 761.66 & 538.28 & 223.38 & 29.29 & 71.15 & 70.67 & 0.76 & 1.12 & 169.66 & 25.32 & 12.99 & 47.37 \\
\hline GT & 587.95 & 563.85 & 24.09 & 3.16 & 7.67 & 95.90 & 1.28 & 1.40 & 30.75 & 40.51 & 56.85 & 9.38 \\
\hline HPSH & 38.69 & 35.97 & 2.72 & 0.36 & 0.87 & 93.03 & 1.28 & 1.57 & 3.47 & 7.20 & 67.48 & 22.66 \\
\hline RH & 29.28 & 26.76 & 2.52 & 0.33 & 0.80 & 91.38 & 1.28 & 1.51 & 3.22 & 2.97 & 47.98 & 17.97 \\
\hline HPEvap & 48.27 & 44.68 & 3.59 & 0.47 & 1.15 & 92.55 & 1.28 & 1.51 & 4.60 & 5.58 & 54.81 & 17.97 \\
\hline HPEcon & 32.41 & 28.04 & 4.36 & 0.57 & 1.39 & 86.53 & 1.28 & 1.58 & 5.59 & 2.79 & 33.29 & 23.44 \\
\hline IPSH & 0.53 & 0.19 & 0.34 & 0.04 & 0.11 & 35.48 & 1.28 & 4.78 & 0.44 & 0.22 & 33.33 & 273.44 \\
\hline IPEvap & 6.73 & 6.14 & 0.59 & 0.08 & 0.19 & 91.29 & 1.28 & 1.80 & 0.75 & 2.44 & 76.49 & 40.63 \\
\hline IPEcon & 1.48 & 1.01 & 0.47 & 0.06 & 0.15 & 68.31 & 1.28 & 2.05 & 0.60 & 0.18 & 23.08 & 60.16 \\
\hline LPSH & 1.58 & 1.08 & 0.50 & 0.07 & 0.16 & 68.27 & 1.28 & 2.38 & 0.64 & 0.55 & 46.22 & 85.94 \\
\hline LPEvap & 19.47 & 16.10 & 3.36 & 0.44 & 1.07 & 82.72 & 1.28 & 1.86 & 4.31 & 5.08 & 54.10 & 45.31 \\
\hline LPEcon & 13.39 & 8.76 & 4.63 & 0.61 & 1.48 & 65.40 & 1.28 & 2.25 & 5.93 & 2.59 & 30.40 & 75.78 \\
\hline HPST & 34.14 & 32.25 & 1.89 & 0.25 & 0.60 & 94.47 & 1.61 & 1.91 & 3.04 & 6.55 & 68.30 & 18.63 \\
\hline MPST & 40.18 & 37.97 & 2.20 & 0.29 & 0.70 & 94.51 & 1.61 & 1.89 & 3.55 & 7.22 & 67.04 & 17.39 \\
\hline LPST & 81.89 & 74.55 & 7.33 & 0.96 & 2.34 & 91.05 & 1.68 & 1.99 & 12.33 & 10.82 & 46.74 & 18.45 \\
\hline P1 & 0.004 & 0.003 & 0.001 & 0.0001 & 0.0003 & 80.27 & 1.58 & 39.21 & 0.00 & 0.12 & 100.00 & 2381.65 \\
\hline P2 & 0.02 & 0.02 & 0.005 & 0.001 & 0.002 & 80.28 & 1.58 & 10.63 & 0.01 & 0.17 & 94.44 & 572.78 \\
\hline P3 & 1.35 & 1.08 & 0.27 & 0.03 & 0.08 & 80.29 & 1.58 & 3.19 & 0.42 & 1.32 & 75.86 & 101.90 \\
\hline P4 & 0.05 & 0.04 & 0.01 & 0.002 & 0.00 & 78.35 & 1.58 & 4.92 & 0.02 & 0.12 & 85.71 & 211.39 \\
\hline Cond & - & - & 9.41 & 1.23 & 3.00 & - & 22.46 & - & 211.24 & 1.92 & 0.90 & - \\
\hline $\begin{array}{l}\text { Cooling } \\
\text { Tower }\end{array}$ & - & - & 9.72 & 1.27 & 3.10 & - & 24.38 & - & 237.02 & 2.32 & 0.97 & - \\
\hline Deaerator & 0.54 & 0.51 & 0.03 & 0.004 & 0.01 & 93.77 & 1.92 & 3.77 & 0.06 & 0.87 & 93.55 & 96.35 \\
\hline mixer 1 & 2.20 & 1.96 & 0.24 & 0.03 & 0.08 & 89.19 & 1.61 & 1.81 & 0.38 & - & - & 12.42 \\
\hline mixer 2 & 0.70 & 0.65 & 0.05 & 0.01 & 0.02 & 93.18 & 1.61 & 1.73 & 0.08 & - & - & 7.45 \\
\hline mixer 3 & 10.53 & 10.10 & 0.43 & 0.06 & 0.14 & 95.80 & 1.28 & 1.33 & 0.55 & - & - & 3.91 \\
\hline TOTAL & 762.72 & 437.27 & 313.95 & 41.16 & 100.00 & 57.33 & 0.76 & 1.69 & 238.12 & 162.30 & - & - \\
\hline
\end{tabular}


Table A8. NGCC power plant with dry cooling results at the component level.

\begin{tabular}{|c|c|c|c|c|c|c|c|c|c|c|c|c|}
\hline Component & $\dot{E}_{F, k}(\mathrm{MW})$ & $\dot{E}_{P, k}(\mathrm{MW})$ & $\dot{E}_{D, k}(\mathrm{MW})$ & $y_{D, k}(\%)$ & $y_{D, k} *(\%)$ & $\varepsilon_{k}(\%)$ & $c_{F, k}($ Cent $/ \mathrm{MJ})$ & $c_{P, k}($ Cent/MJ) & $\dot{C}_{D, k}($ Cent $/ \mathrm{s})$ & $Z_{K}($ Cent/s) & $f_{K}(\%)$ & $r_{K}(\%)$ \\
\hline Compressor & 274.49 & 262.49 & 12.00 & 1.55 & 3.78 & 95.63 & 1.40 & 1.59 & 16.75 & 35.02 & 67.65 & 13.57 \\
\hline CC & 774.51 & 547.36 & 227.15 & 29.29 & 71.57 & 70.67 & 0.76 & 1.12 & 172.52 & 25.01 & 12.66 & 47.37 \\
\hline GT & 597.86 & 573.37 & 24.50 & 3.16 & 7.72 & 95.90 & 1.27 & 1.40 & 31.16 & 40.02 & 56.22 & 10.24 \\
\hline HPSH & 39.29 & 36.58 & 2.71 & 0.35 & 0.85 & 93.10 & 1.27 & 1.56 & 3.45 & 7.12 & 67.36 & 22.83 \\
\hline $\mathrm{RH}$ & 29.79 & 27.21 & 2.58 & 0.33 & 0.81 & 91.35 & 1.27 & 1.51 & 3.28 & 3.16 & 49.07 & 18.90 \\
\hline HPEvap & 49.09 & 45.43 & 3.66 & 0.47 & 1.15 & 92.55 & 1.28 & 1.50 & 4.67 & 5.59 & 54.48 & 17.19 \\
\hline HPEcon & 32.95 & 28.52 & 4.44 & 0.57 & 1.40 & 86.53 & 1.28 & 1.57 & 5.66 & 2.80 & 33.10 & 22.66 \\
\hline IPSH & 0.54 & 0.19 & 0.35 & 0.04 & 0.11 & 35.48 & 1.28 & 4.75 & 0.44 & 0.22 & 33.33 & 271.09 \\
\hline IPEvap & 6.84 & 6.25 & 0.60 & 0.08 & 0.19 & 91.29 & 1.28 & 1.79 & 0.76 & 2.45 & 76.32 & 39.84 \\
\hline IPEcon & 1.50 & 1.03 & 0.48 & 0.06 & 0.15 & 68.31 & 1.28 & 2.04 & 0.61 & 0.18 & 22.78 & 59.38 \\
\hline LPSH & 1.61 & 1.10 & 0.51 & 0.07 & 0.16 & 68.27 & 1.28 & 2.37 & 0.65 & 0.55 & 45.83 & 85.16 \\
\hline LPEvap & 19.80 & 16.38 & 3.42 & 0.44 & 1.08 & 82.72 & 1.28 & 1.85 & 4.37 & 5.09 & 53.81 & 44.53 \\
\hline LPEcon & 13.62 & 8.90 & 4.71 & 0.61 & 1.48 & 65.40 & 1.28 & 2.24 & 6.01 & 2.59 & 30.12 & 75.00 \\
\hline HPST & 34.71 & 32.80 & 1.92 & 0.25 & 0.60 & 94.47 & 1.60 & 1.89 & 3.07 & 6.47 & 67.82 & 18.13 \\
\hline MPST & 40.86 & 38.61 & 2.24 & 0.29 & 0.71 & 94.51 & 1.60 & 1.88 & 3.60 & 7.13 & 66.45 & 17.50 \\
\hline LPST & 83.27 & 75.81 & 7.46 & 0.96 & 2.35 & 91.05 & 1.67 & 1.98 & 12.48 & 10.69 & 46.14 & 18.56 \\
\hline P1 & 0.004 & 0.003 & 0.001 & 0.0001 & 0.0003 & 80.26 & 1.57 & 38.58 & 0.00 & 0.12 & 100.00 & 2357.32 \\
\hline P2 & 0.02 & 0.02 & 0.005 & 0.001 & 0.002 & 80.28 & 1.57 & 10.48 & 0.01 & 0.17 & 94.44 & 567.52 \\
\hline P3 & 1.37 & 1.10 & 0.27 & 0.03 & 0.09 & 80.29 & 1.57 & 3.16 & 0.42 & 1.32 & 75.86 & 101.27 \\
\hline $\mathrm{P} 4$ & 0.05 & 0.04 & 0.01 & 0.002 & 0.004 & 78.36 & 1.57 & 4.86 & 0.02 & 0.12 & 85.71 & 209.55 \\
\hline AC cond & 107.06 & - & 17.57 & 2.26 & 5.53 & - & 0.32 & - & 5.59 & 12.86 & 69.70 & - \\
\hline Deaerator & 0.55 & 0.51 & 0.03 & 0.004 & 0.01 & 93.77 & 1.91 & 3.71 & 0.07 & 0.86 & 92.47 & 94.24 \\
\hline mixer 1 & 2.24 & 2.00 & 0.24 & 0.03 & 0.08 & 89.19 & 1.60 & 1.80 & 0.39 & - & - & 12.50 \\
\hline mixer 2 & 0.71 & 0.66 & 0.05 & 0.01 & 0.02 & 93.18 & 1.60 & 1.72 & 0.08 & - & - & 7.50 \\
\hline mixer 3 & 11.17 & 10.69 & 0.48 & 0.06 & 0.15 & 95.69 & 1.27 & 1.33 & 0.61 & - & - & 4.72 \\
\hline TOTAL & 775.59 & 437.45 & 317.36 & 40.92 & 100.00 & 56.40 & 0.76 & 1.73 & 240.70 & 169.53 & - & - \\
\hline
\end{tabular}


Table A9. ISCC power plant with wet cooling results at the component level.

\begin{tabular}{|c|c|c|c|c|c|c|c|c|c|c|c|c|}
\hline Component & $\dot{E}_{F, k}(\mathrm{MW})$ & $\dot{E}_{P, k}(\mathrm{MW})$ & $\dot{E}_{D, k}(\mathrm{MW})$ & $y_{D, k}(\%)$ & $y_{D, k} *(\%)$ & $\varepsilon_{k}(\%)$ & $c_{F, k}($ Cent $/ \mathrm{MJ})$ & $c_{P, k}($ Cent $/ \mathrm{MJ})$ & $\dot{C}_{D, k}($ Cent $/ \mathrm{s})$ & $Z_{K}($ Cent/s) & $f_{K}(\%)$ & $r_{K}(\%)$ \\
\hline Compressor & 212.46 & 203.36 & 9.09 & 1.54 & 5.85 & 95.72 & 1.36 & 1.53 & 12.39 & 22.61 & 64.60 & 12.50 \\
\hline CC & 590.23 & 419.06 & 171.17 & 28.94 & 110.17 & 71.00 & 0.76 & 1.11 & 130.01 & 16.15 & 11.05 & 46.05 \\
\hline GT & 447.95 & 428.33 & 19.62 & 3.32 & 12.63 & 95.62 & 1.24 & 1.36 & 24.43 & 25.84 & 51.40 & 9.68 \\
\hline HP2 SH & 67.59 & 64.23 & 3.36 & 0.57 & 2.17 & 95.02 & 1.24 & 1.48 & 4.19 & 10.94 & 72.31 & 19.35 \\
\hline HP2 Evap & 34.47 & 31.79 & 2.68 & 0.45 & 1.73 & 92.22 & 1.24 & 1.47 & 3.34 & 3.87 & 53.68 & 18.55 \\
\hline IP2 SH & 1.81 & 1.62 & 0.19 & 0.03 & 0.13 & 89.24 & 1.24 & 1.70 & 0.24 & 0.50 & 67.57 & 37.10 \\
\hline HP2 Econ & 15.39 & 13.21 & 2.18 & 0.37 & 1.40 & 85.85 & 1.24 & 1.52 & 2.71 & 0.95 & 25.96 & 22.58 \\
\hline IP2 Evap & 7.27 & 6.82 & 0.44 & 0.08 & 0.29 & 93.89 & 1.24 & 1.62 & 0.55 & 1.99 & 78.35 & 30.65 \\
\hline IP2 Econ & 9.24 & 7.11 & 2.13 & 0.36 & 1.37 & 76.90 & 1.24 & 1.69 & 2.66 & 0.54 & 16.88 & 36.29 \\
\hline LP2 Evap & 14.76 & 12.50 & 2.26 & 0.38 & 1.45 & 84.70 & 1.24 & 1.78 & 2.81 & 3.89 & 58.06 & 43.55 \\
\hline LP2 Econ & 0.64 & 0.53 & 0.12 & 0.02 & 0.08 & 81.88 & 1.24 & 2.37 & 0.15 & 0.45 & 75.00 & 91.13 \\
\hline Preheater & 14.91 & 11.28 & 3.63 & 0.61 & 2.33 & 75.67 & 1.24 & 2.10 & 4.52 & 5.17 & 53.35 & 69.35 \\
\hline HP1 SH & 15.24 & 13.91 & 1.33 & 0.22 & 0.85 & 91.29 & 0.96 & 1.29 & 1.27 & 3.39 & 72.75 & 34.38 \\
\hline HP1 Evap & 66.73 & 61.11 & 5.63 & 0.95 & 3.62 & 91.57 & 0.96 & 1.21 & 5.40 & 10.08 & 65.12 & 26.04 \\
\hline HP1 Econ & 36.42 & 30.17 & 6.25 & 1.06 & 4.02 & 82.83 & 0.96 & 1.23 & 6.00 & 2.08 & 25.74 & 28.13 \\
\hline IP1 SH & 1.69 & 1.48 & 0.20 & 0.03 & 0.13 & 87.85 & 0.96 & 1.40 & 0.20 & 0.46 & 69.70 & 45.83 \\
\hline IP1 Evap & 19.93 & 16.99 & 2.94 & 0.50 & 1.89 & 85.25 & 0.96 & 1.23 & 2.82 & 1.80 & 38.96 & 28.13 \\
\hline IP1 Econ & 4.95 & 3.71 & 1.25 & 0.21 & 0.80 & 74.85 & 0.96 & 1.35 & 1.19 & 0.24 & 16.78 & 40.63 \\
\hline P1 & 2.84 & 2.15 & 0.69 & 0.12 & 0.44 & 75.87 & 1.57 & 3.03 & 1.08 & 2.07 & 65.71 & 92.99 \\
\hline Solar field & 263.99 & 142.81 & 121.18 & - & - & 54.10 & - & 0.93 & - & 132.50 & - & - \\
\hline ST1 & 50.72 & 47.00 & 3.73 & 0.63 & 2.40 & 92.65 & 1.45 & 1.72 & 5.42 & 7.13 & 56.81 & 18.62 \\
\hline ST2 & 79.91 & 72.02 & 7.88 & 1.33 & 5.07 & 90.14 & 1.45 & 1.74 & 11.45 & 9.22 & 44.61 & 20.00 \\
\hline ST3 & 48.27 & 43.01 & 5.26 & 0.89 & 3.38 & 89.11 & 1.47 & 1.80 & 7.71 & 6.76 & 46.72 & 22.45 \\
\hline ST4 & 74.34 & 64.89 & 9.45 & 1.60 & 6.08 & 87.29 & 1.47 & 1.81 & 13.85 & 8.60 & 38.31 & 23.13 \\
\hline P2 & 0.02 & 0.01 & 0.005 & 0.001 & 0.003 & 73.36 & 1.57 & 9.82 & 0.01 & 0.10 & 90.91 & 525.48 \\
\hline P3 & 1.03 & 0.75 & 0.27 & 0.05 & 0.18 & 73.43 & 1.57 & 3.37 & 0.43 & 0.93 & 68.38 & 114.65 \\
\hline P4 & 2.29 & 1.70 & 0.59 & 0.10 & 0.38 & 74.23 & 1.57 & 3.15 & 0.93 & 1.76 & 65.43 & 100.64 \\
\hline P5 & 0.13 & 0.09 & 0.04 & 0.01 & 0.03 & 68.99 & 1.57 & 3.54 & 0.06 & 0.11 & 64.71 & 125.48 \\
\hline Cond & - & - & 9.35 & 1.58 & 6.02 & - & 32.29 & - & 301.89 & 2.57 & 0.84 & - \\
\hline $\begin{array}{l}\text { Cooling } \\
\text { Tower }\end{array}$ & - & - & 22.70 & 3.84 & 14.61 & - & 34.86 & - & 791.16 & 2.74 & 0.35 & - \\
\hline Deaerator & 8.06 & 7.25 & 0.82 & 0.14 & 0.53 & 89.86 & 1.83 & 2.23 & 1.49 & 1.46 & 49.49 & 21.86 \\
\hline mixer 1 & 0.40 & 0.38 & 0.02 & 0.004 & 0.02 & 94.00 & 1.35 & 1.44 & 0.03 & - & - & 6.67 \\
\hline mixer 2 & 4.51 & 4.36 & 0.15 & 0.03 & 0.10 & 96.58 & 1.34 & 1.39 & 0.21 & - & - & 3.73 \\
\hline mixer 3 & 15.32 & 12.65 & 2.67 & 0.45 & 1.72 & 82.55 & 1.43 & 1.73 & 3.83 & - & - & 20.98 \\
\hline mixer 4 & 1.27 & 1.24 & 0.03 & 0.01 & 0.02 & 97.36 & 1.45 & 1.49 & 0.05 & - & - & 2.76 \\
\hline mixer 5 & 0.13 & 0.10 & 0.03 & 0.01 & 0.02 & 74.15 & 1.83 & 2.46 & 0.06 & - & - & 34.43 \\
\hline TOTAL & 591.52 & 436.50 & 155.37 & 26.27 & 100.00 & 73.79 & 0.76 & 1.68 & 117.75 & 286.92 & - & - \\
\hline
\end{tabular}


Table A10. ISCC power plant with dry cooling results at the component level.

\begin{tabular}{|c|c|c|c|c|c|c|c|c|c|c|c|c|}
\hline Component & $\dot{E}_{F, k}(\mathrm{MW})$ & $\dot{E}_{P, k}(\mathrm{MW})$ & $\dot{E}_{D, k}(\mathrm{MW})$ & $y_{D, k}(\%)$ & $y_{D, k} *(\%)$ & $\varepsilon_{k}(\%)$ & $c_{F, k}($ Cent/MJ $)$ & $c_{P, k}($ Cent/MJ $)$ & $\dot{C}_{D, k}($ Cent $/ \mathbf{s})$ & $Z_{K}($ Cent/s) & $f_{K}(\%)$ & $r_{K}(\%)$ \\
\hline Compressor & 243.80 & 233.72 & 10.09 & 1.58 & 6.42 & 95.86 & 1.36 & 1.52 & 13.68 & 24.73 & 64.38 & 11.76 \\
\hline CC & 635.05 & 454.56 & 180.49 & 28.36 & 114.97 & 71.58 & 0.76 & 1.10 & 137.08 & 17.66 & 11.41 & 44.74 \\
\hline GT & 505.49 & 483.14 & 22.35 & 3.51 & 14.24 & 95.58 & 1.24 & 1.36 & 27.72 & 28.26 & 50.48 & 9.68 \\
\hline HP2 SH & 67.32 & 63.87 & 3.45 & 0.54 & 2.19 & 94.88 & 1.24 & 1.47 & 4.27 & 10.62 & 71.32 & 18.55 \\
\hline HP2 Evap & 37.60 & 34.65 & 2.95 & 0.46 & 1.88 & 92.15 & 1.24 & 1.46 & 3.66 & 4.09 & 52.77 & 17.74 \\
\hline $\mathrm{IP} 2 \mathrm{SH}$ & 1.94 & 1.73 & 0.21 & 0.03 & 0.13 & 89.12 & 1.24 & 1.69 & 0.26 & 0.52 & 66.67 & 36.29 \\
\hline HP2 Econ & 16.11 & 13.81 & 2.30 & 0.36 & 1.46 & 85.74 & 1.24 & 1.52 & 2.85 & 0.97 & 25.39 & 22.58 \\
\hline IP2 Evap & 8.26 & 7.75 & 0.52 & 0.08 & 0.33 & 93.76 & 1.24 & 1.60 & 0.64 & 2.15 & 77.06 & 29.03 \\
\hline IP2 Econ & 9.47 & 7.27 & 2.21 & 0.35 & 1.41 & 76.70 & 1.24 & 1.69 & 2.74 & 0.54 & 16.46 & 36.29 \\
\hline LP2 Evap & 16.35 & 13.81 & 2.54 & 0.40 & 1.62 & 84.46 & 1.24 & 1.77 & 3.15 & 4.13 & 56.73 & 42.74 \\
\hline LP2 Econ & 0.67 & 0.54 & 0.12 & 0.02 & 0.08 & 81.32 & 1.24 & 2.36 & 0.15 & 0.45 & 75.00 & 90.32 \\
\hline Preheater & 14.17 & 10.62 & 3.55 & 0.56 & 2.26 & 74.94 & 1.24 & 2.02 & 4.40 & 3.85 & 46.67 & 62.90 \\
\hline HP1 SH & 15.24 & 13.91 & 1.33 & 0.21 & 0.85 & 91.29 & 0.95 & 1.28 & 1.26 & 3.34 & 72.61 & 34.74 \\
\hline HP1 Evap & 66.73 & 61.11 & 5.63 & 0.88 & 3.58 & 91.57 & 0.95 & 1.20 & 5.33 & 9.96 & 65.14 & 26.32 \\
\hline HP1 Econ & 36.42 & 30.17 & 6.25 & 0.98 & 3.98 & 82.83 & 0.95 & 1.21 & 5.92 & 2.05 & 25.72 & 27.37 \\
\hline IP1 SH & 1.69 & 1.48 & 0.20 & 0.03 & 0.13 & 87.85 & 0.95 & 1.38 & 0.19 & 0.45 & 70.31 & 45.26 \\
\hline IP1 Evap & 19.93 & 16.99 & 2.94 & 0.46 & 1.87 & 85.25 & 0.95 & 1.22 & 2.78 & 1.78 & 39.04 & 28.42 \\
\hline IP1 Econ & 4.95 & 3.71 & 1.25 & 0.20 & 0.79 & 74.85 & 0.95 & 1.33 & 1.18 & 0.23 & 16.31 & 40.00 \\
\hline P1 & 2.84 & 2.15 & 0.69 & 0.11 & 0.44 & 75.87 & 1.54 & 2.98 & 1.06 & 2.05 & 65.92 & 93.51 \\
\hline Solar field & 263.99 & 142.81 & 121.18 & - & - & 54.10 & - & 0.92 & - & 130.81 & - & - \\
\hline ST1 & 51.57 & 47.78 & 3.79 & 0.60 & 2.41 & 92.65 & 1.44 & 1.70 & 5.44 & 7.11 & 56.65 & 18.06 \\
\hline ST2 & 81.45 & 73.42 & 8.03 & 1.26 & 5.12 & 90.14 & 1.44 & 1.72 & 11.53 & 9.20 & 44.38 & 19.44 \\
\hline ST3 & 49.60 & 44.20 & 5.40 & 0.85 & 3.44 & 89.11 & 1.45 & 1.78 & 7.84 & 6.79 & 46.41 & 22.76 \\
\hline ST4 & 56.12 & 49.27 & 6.84 & 1.08 & 4.36 & 87.80 & 1.45 & 1.80 & 9.94 & 7.20 & 42.01 & 24.14 \\
\hline P2 & 0.02 & 0.01 & 0.005 & 0.001 & 0.003 & 73.36 & 1.54 & 9.58 & 0.01 & 0.10 & 90.91 & 522.08 \\
\hline P3 & 1.05 & 0.77 & 0.28 & 0.04 & 0.18 & 73.43 & 1.54 & 3.31 & 0.43 & 0.93 & 68.38 & 114.94 \\
\hline P4 & 2.33 & 1.73 & 0.60 & 0.09 & 0.38 & 74.23 & 1.54 & 3.09 & 0.92 & 1.76 & 65.67 & 100.65 \\
\hline P5 & 0.13 & 0.09 & 0.04 & 0.01 & 0.02 & 69.75 & 1.54 & 3.32 & 0.06 & 0.10 & 62.50 & 115.58 \\
\hline AC Cond & 52.42 & - & 22.40 & 3.52 & 14.27 & 1.91 & 1.47 & - & 32.91 & 21.48 & 39.49 & - \\
\hline Deaerator & 8.25 & 7.42 & 0.83 & 0.13 & 0.53 & 89.89 & 1.80 & 2.21 & 1.50 & 1.49 & 49.83 & 22.78 \\
\hline mixer 1 & 0.44 & 0.41 & 0.03 & 0.004 & 0.02 & 94.13 & 1.33 & 1.41 & 0.03 & - & - & 6.02 \\
\hline mixer 2 & 4.78 & 4.62 & 0.16 & 0.03 & 0.10 & 96.61 & 1.32 & 1.37 & 0.21 & - & - & 3.79 \\
\hline mixer 3 & 13.17 & 10.90 & 2.26 & 0.36 & 1.44 & 82.81 & 1.42 & 1.71 & 3.21 & - & - & 20.42 \\
\hline mixer 4 & 1.31 & 1.28 & 0.03 & 0.01 & 0.02 & 97.36 & 1.44 & 1.48 & 0.05 & - & - & 2.78 \\
\hline mixer 5 & 0.16 & 0.12 & 0.04 & 0.01 & 0.03 & 74.11 & 1.80 & 2.43 & 0.08 & - & - & 35.00 \\
\hline TOTAL & 636.44 & 437.12 & 156.99 & 24.67 & 100.00 & 68.68 & 0.76 & 1.80 & 118.97 & 304.82 & - & - \\
\hline
\end{tabular}




\section{References}

1. Semertzidis, T.; Spataru, C.; Bleischwitz, R. Cross-sectional integration of the water-energy nexus in Brazil. J. Sustain. Dev. Energy Water Environ. Syst. 2018, 6, 114-128. [CrossRef]

2. Lin, L.; Chen, Y. Evaluation of Future Water Use for Electricity Generation under Different Energy Development Scenarios in China. Sustainability 2017, 10, 30. [CrossRef]

3. Rijsberman, F.R. Water scarcity: Fact or fiction? Agric. Water Manag. 2006, 80, 5-22. [CrossRef]

4. Bieber, N.; Ker, J.H.; Wang, X.; Triantafyllidis, C.; van Dam, K.H.; Koppelaar, R.H.; Shah, N. Sustainable planning of the energy-water-food nexus using decision making tools. Energy Policy 2018, 113, 584-607. [CrossRef]

5. Collins, R.; Kristensen, P.; Thyssen, N. Water Resources Across Europe-Confronting Water Scarcity and Drought; European Environment Agency: Copenhagen, Denmark, 2009. [CrossRef]

6. Ali, B.; Kumar, A. Development of life cycle water-demand coefficients for coal-based power generation technologies. Energy Convers. Manag. 2015, 90, 247-260. [CrossRef]

7. Förster, H.; Lilliestam, J. Modeling thermoelectric power generation in view of climate change. Reg. Environ. Chang. 2010, 10, 327-338. [CrossRef]

8. Dodder, R.S. A review of water use in the U.S. electric power sector: Insights from systems-level perspectives. Curr. Opin. Chem. Eng. 2014, 5, 7-14. [CrossRef]

9. Scanlon, B.R.; Duncan, I.; Reedy, R.C. Drought and the water-energy nexus in Texas. Environ. Res. Lett. 2013, 8. [CrossRef]

10. Hadian, S.; Madani, K. The Water Demand of Energy: Implications for Sustainable Energy Policy Development. Sustainability 2013, 5, 4674-4687. [CrossRef]

11. Miara, A. Thermal effluent from the power sector: An analysis of once-through cooling system impacts on surface water temperature. Environ. Res. Lett. 2013. [CrossRef]

12. Zhai, H.; Rubin, E.S. Performance and cost of wet and dry cooling systems for pulverized coal power plants with and without carbon capture and storage. Energy Policy 2010, 38, 5653-5660. [CrossRef]

13. Thopil, G.A.; Pouris, A. A 20 year forecast of water usage in electricity generation for South Africa amidst water scarce conditions. Renew. Sustain. Energy Rev. 2016, 62, 1106-1121. [CrossRef]

14. Rezaei, E.; Shafiei, S.; Abdollahnezhad, A. Reducing water consumption of an industrial plant cooling unit using hybrid cooling tower. Energy Convers. Manag. 2010, 51, 311-319. [CrossRef]

15. Alqahtani, B.J.; Patino-Echeverri, D. Integrated Solar Combined Cycle Power Plants: Paving the way for thermal solar. Appl. Energy 2016, 169, 1-23. [CrossRef]

16. Frías, P.; Becerro González, F.J.; Junquera Delgado, A. Integración de plantas termosolares en ciclos combinados. Hibridación de fuentes renovables y fósiles en la generación eléctrica. Anales de Mecánica y Electricidad. 2013, XC, 27-32.

17. Adem, U. A case study of PV-wind-diesel-battery hybrid system. J. Energy Syst. 2017, 1, 138-147. [CrossRef]

18. Williams, C.R.; Rasul, M.G. Feasibility of a hybrid cooling system in a thermal power plant. In Proceedings of the 3rd IASME/WSEAS international conference on Energy \& environment, Cambridge, UK, 23-25 February 2008; pp. 124-129.

19. Achour, L.; Bouharkat, M.; Behar, O. Performance assessment of an integrated solar combined cycle in the southern of Algeria. Energy Rep. 2018, 4, 207-217. [CrossRef]

20. Binamer, A.O. Al-Abdaliya integrated solar combined cycle power plant: Case study of Kuwait, part, I. Renew. Energy 2019, 131, 923-937. [CrossRef]

21. Calise, F.; d'Accadia, M.D.; Libertini, L.; Vicidomini, M. Thermoeconomic analysis of an integrated solar combined cycle power plant. Energy Convers. Manag. 2018, 171, 1038-1051. [CrossRef]

22. Bonforte, G.; Buchgeister, J.; Manfrida, G.; Petela, K. Exergoeconomic and exergoenvironmental analysis of an integrated solar gas turbine/combined cycle power plant. Energy 2018, 156, 352-359. [CrossRef]

23. Ameri, M.; Mohammadzadeh, M. Thermodynamic, thermoeconomic and life cycle assessment of a novel integrated solar combined cycle (ISCC) power plant. Sustain. Energy Technol. Assess. 2018, 27, 192-205. [CrossRef]

24. Scanlon, B.R.; Duncan, I.; Reedy, R.C.; Venkatesh, A.; Jaramillo, P.; Griffin, W.M. Marginal costs of water savings from cooling system retrofits: A case study for Texas power plants 2008, Environmental Research 
Letters. Available online: https://iopscience.iop.org/article/10.1088/1748-9326/11/10/104004/meta (accessed on 7 April 2019).

25. Reddy, V.S.; Kaushik, S.C.; Tyagi, S.K.; Panwar, N. An Approach to Analyse Energy and Exergy Analysis of Thermal Power Plants: A Review. Smart Grid Renew. Energy 2010, 1, 143-152. [CrossRef]

26. Petrakopoulou, F.; Tsatsaronis, G.; Morosuk, T.; Carassai, A. Conventional and advanced exergetic analyses applied to a combined cycle power plant. Energy 2012, 41, 146-152. [CrossRef]

27. Kaushik, S.C.; Reddy, V.S.; Tyagi, S.K. Energy and exergy analyses of thermal power plants: A review. Renew. Sustain. Energy Rev. 2011, 15, 1857-1872. [CrossRef]

28. Kotas, T.J. Introduction. Exergy Method Therm. Plant Anal. 1985. [CrossRef]

29. Zhao, Y.; Wang, S.; Ge, M.; Li, Y.; Yang, Y. Energy and exergy analysis of thermoelectric generator system with humidified flue gas. Energy Convers. Manag. 2018, 156, 140-149. [CrossRef]

30. Verma, Y.; Kaurase, K.P. Exergy Analysis of Thermal Power Plant: A Review. N. Eng. J. Med. 2013, 2, 668-673. [CrossRef]

31. Koroneos, C.; Polyzakis, A.; Xydis, G.; Stylos, N.; Nanaki, E. Exergy analysis for a proposed binary geothermal power plant in Nisyros Island, Greece. Geothermics 2017, 70, 38-46. [CrossRef]

32. Sahoo, U.; Kumar, R.; Singh, S.K.; Tripathi, A.K. Energy, exergy, economic analysis and optimization of polygeneration hybrid solar-biomass system. Appl. Therm. Eng. 2018, 145, 685-692. [CrossRef]

33. Wang, L.; Yang, Y.; Dong, C.; Yang, Z.; Xu, G.; Wu, L. Exergoeconomic evaluation of a modern ultra-supercritical power plant. Energies 2012, 5, 3381-3397. [CrossRef]

34. Bejan, A.; Tsatsaronis, G.; Moran, M. Thermal Design and Optimization; Wiley-Interscience: New York, NY, USA, 1996.

35. Petrakopoulou, F. Comparative Evaluation of Power Plants with $\mathrm{CO}^{2}$ Capture: Thermodynamic, Economic and Environmental Performance; Institut für Energietechnik: Amberg, Germany, 2010.

(C) 2019 by the authors. Licensee MDPI, Basel, Switzerland. This article is an open access article distributed under the terms and conditions of the Creative Commons Attribution (CC BY) license (http:/ / creativecommons.org/licenses/by/4.0/). 